\title{
A Century of WWV
}

\author{
Glenn K. Nelson \\ National Institute of Standards and Technology, Radio Station WWV, \\ Fort Collins, CO 80524, USA \\ glenn.nelson@nist.gov
}

WWV was established as a radio station on October 1, 1919, with the issuance of the call letters by the U.S. Department of Commerce. This paper will observe the upcoming 100th anniversary of that event by exploring the events leading to the founding of WWV, the various early experiments and broadcasts, its official debut as a service of the National Bureau of Standards, and its role in frequency and time dissemination over the past century.

Key words: broadcasting; frequency; radio; standards; time.

Accepted: September 6, 2019

Published: September 24, 2019

https://doi.org/10.6028/jres.124.025

\section{Introduction}

WWV is the high-frequency radio broadcast service that disseminates time and frequency information from the National Institute of Standards and Technology (NIST), part of the U.S. Department of Commerce. WWV has been performing this service since the early 1920s, and, in 2019, it is celebrating the 100th anniversary of the issuance of its call sign.

\section{Radio Pioneers}

Other radio transmissions predate WWV by decades. Guglielmo Marconi and others were conducting radio research in the late 1890s, and in 1901, Marconi claimed to have received a message sent across the Atlantic Ocean, the letter "S" in telegraphic code [1]. Radio was called "wireless telegraphy" in those days and was, if not commonplace, viewed as an emerging technology. However, these transmissions were usually not intended for a wide audience; in fact, in an attempt to establish a monopoly, for a time, the Marconi Company would not receive or retransmit messages that did not originate from Marconi-owned equipment [2]. The term "broadcasting" was not used to describe these point-to-point transmissions; it hearkens back to a farmhand sowing seed by flinging it by hand across the field, without regard for rows or farrows.

The U.S. Navy was one of the early adopters of this new technology, recognizing the tremendous advantage radio brought to communication from land to ships and from ship to ship. Admiral George Dewey stated in 1904: "But from ships at sea, out of sight of flags or lights, and beyond the sound of guns, the electric wave, projected through space, invisible and inaudible, can alone convey the distant message" [2]. The Navy established a network of radio-transmitting facilities along both coasts of the United States and on numerous overseas bases during the first two decades of the twentieth century. Pertinent to this discussion, the Navy also established the first radio time service in the United States. One of their primary stations, with the call sign NAA, was built in 1912 across the Potomac from Washington, D.C., in Arlington, Virginia. The signal from the station, with its three distinctive towers, was often referred to as 
simply “Arlington Time.” Figure 1 shows an early graphic illustrating the time service from NAA, from the cover of QST Magazine [3].

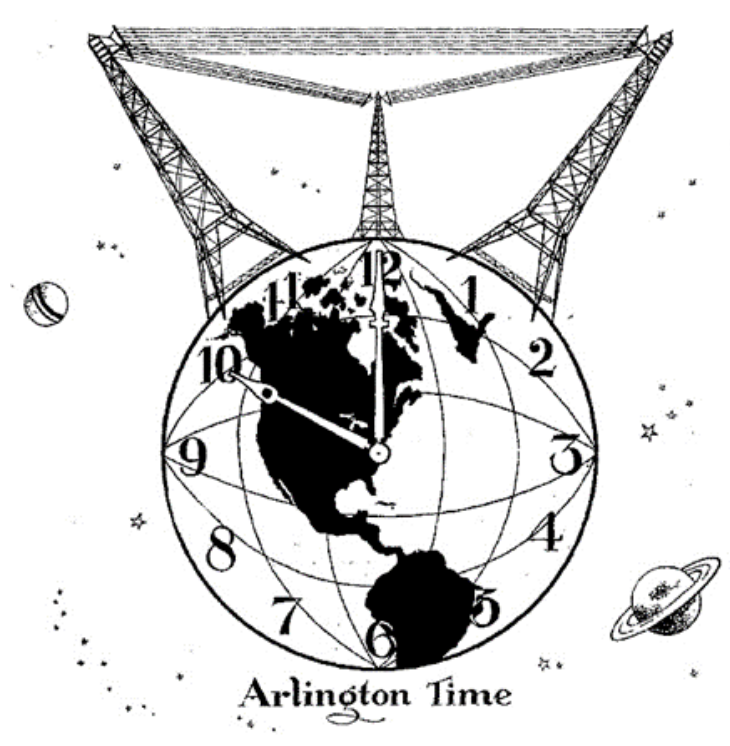

Fig. 1. NAA time broadcast graphic.

Another group of pioneers consisted of amateur radio enthusiasts. In the very early unregulated days of radio, amateurs played a pivotal role in popularizing the new technology. Often using just a few dollars' worth of parts, amateur radio operators, or "hams" (often teenagers), built transmitters and receivers to communicate among themselves and advance the radio arts by their experimentation.

A common element among all these early radio pioneers was the use of telegraphic code. A few had experimented with sending music or the human voice over the airwaves, but the primary use of the technology was point-to-point communication via the series of dots and dashes often referred to as Morse code, developed in the nineteenth century for use in telegraph systems. The first radio stations created the dots and dashes using sparks or arcs, essentially bursts of broadband noise that were then tuned to the transmitting antenna, in the process creating a great deal of electrical noise across the spectrum. Their lowfrequency (below $300 \mathrm{kHz}$ ) operation required huge antenna systems and powerful transmitters for longdistance communication. Hams built smaller versions of these systems, often using an automobile spark coil and rudimentary antennas. Although much less powerful, the sheer number of these amateur operators ensured that the "ether" soon became clogged with signals. An exasperated editorial in the journal Electrical World from 1906, concerned with the interference affecting the U.S. Navy's radio station in Newport, Rhode Island, commented, "the time has now come when in wireless telegraphy it is either regulation or chaos" [4].

The Radio Act of 1912 was an attempt to bring some order to the chaos. The U.S. Department of Commerce was tasked with enforcing the act, which among, other things, required all stations, amateur or commercial, government or military, to be licensed and to operate within their assigned frequency range. The Department of Commerce looked to the National Bureau of Standards (NBS) to develop standards to aid in enforcement.

\section{Laying the Groundwork: Why a Radio Station at NBS?}

Radio experiments at NBS had been happening almost since the beginning of the technology. NBS was founded in 1901 to establish standards of weights and measures for the nation and as the first national physical laboratory. The first documented radio research at NBS occurred in 1905, when Dr. Louis Austin developed a "Detector for Very Small Alternating Currents and Electrical Waves" [5]. The U.S. Navy and the Army Signal Corps set up research laboratories for the study of radio at the NBS facilities in 1908. The 
laboratories were located at a site on Connecticut Avenue in Washington, D.C., which at the time was chosen due to the distance from the noise and interference associated with being downtown [1]. Figure 2 shows an aerial view of the NBS facilities; the photo was taken in 1940.

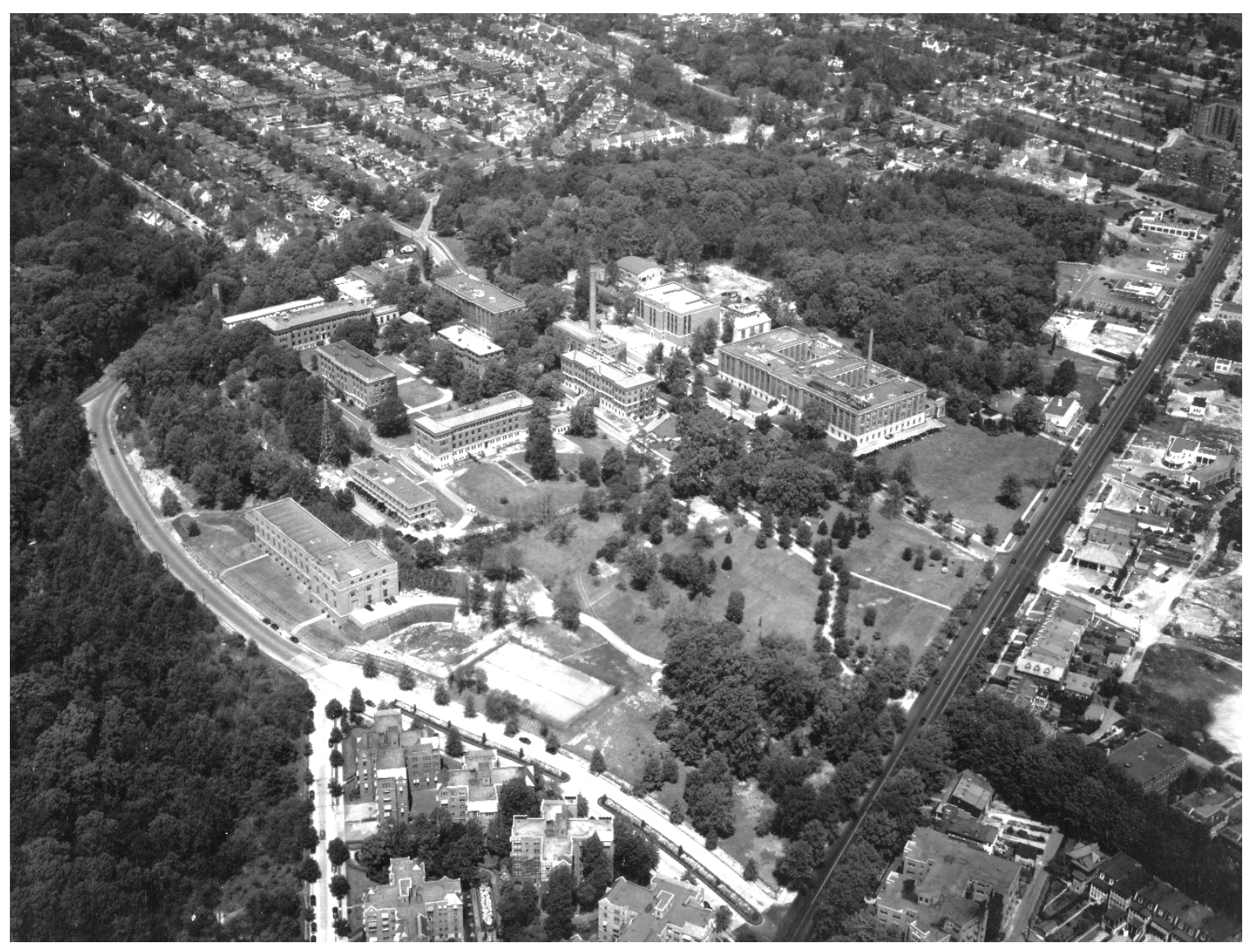

Fig. 2. NBS facilities in Washington, D.C.

The Radio Section of the Electricity Division of NBS was established in 1913 by Frederick Kolster, chief, and Dr. John Dellinger, assistant. In those early years before the establishment of WWV, the Radio Section focused on supporting the Department of Commerce Bureau of Navigation and Bureau of Lighthouses, by designing and calibrating radio-frequency measurement devices, radio transmitters, and radio receivers and by developing a "fog-signaling” early direction-finding system to assist ships in navigating safely in foggy conditions. Figure 3 shows a model of the fog-signaling system. 


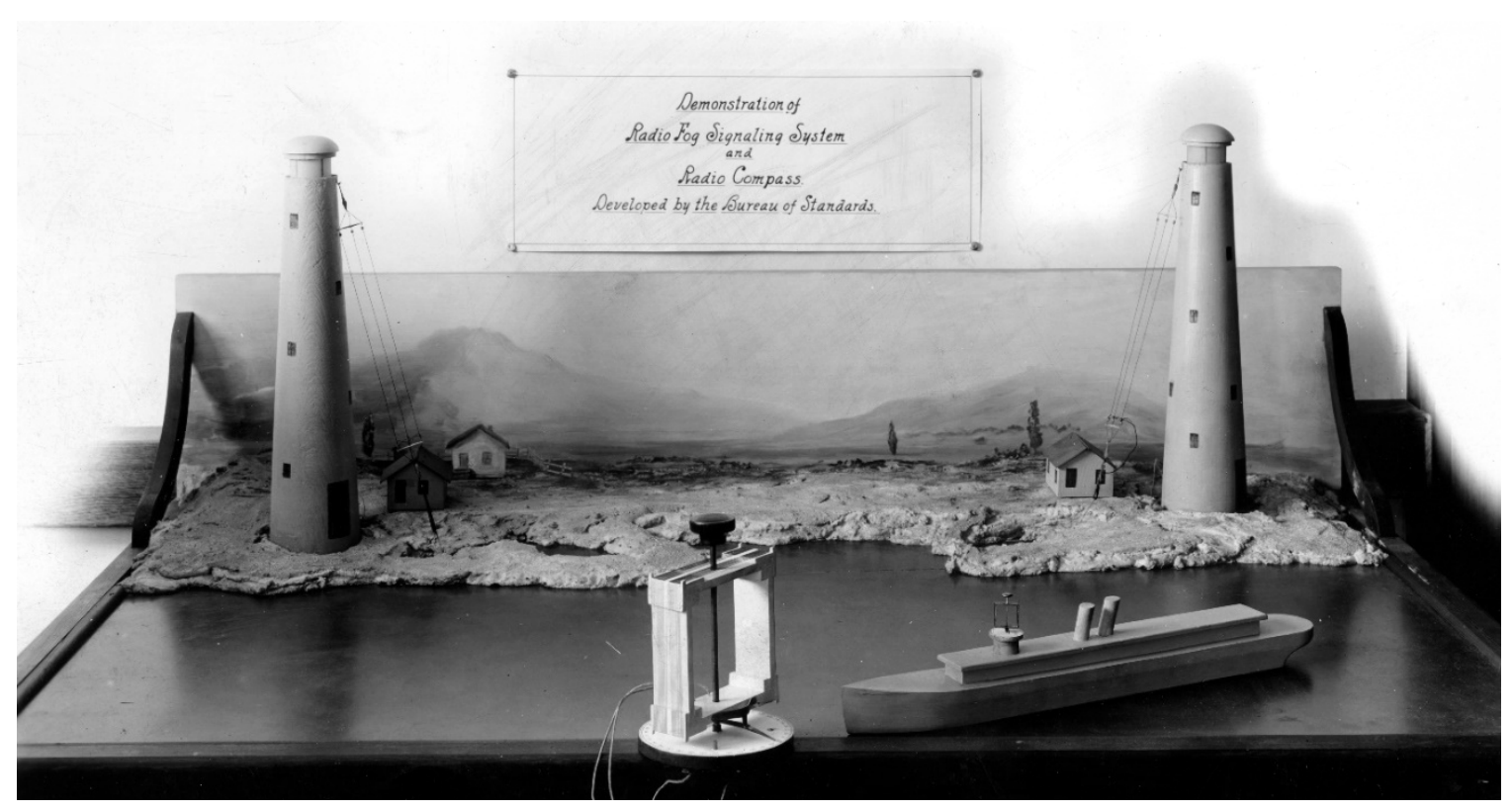

Fig. 3. Model of fog signaling system.

Calibration work was mainly focused on decremeters, instruments designed for measuring the decay, or decrement, of a pulsed radio signal, such as that generated by a spark transmitter typical of the day. Decremeters were essential in minimizing the interference produced as much as possible [1]. A decremeter developed by NBS is shown in Fig. 4. However, the airwaves in America were soon to get much quieter.

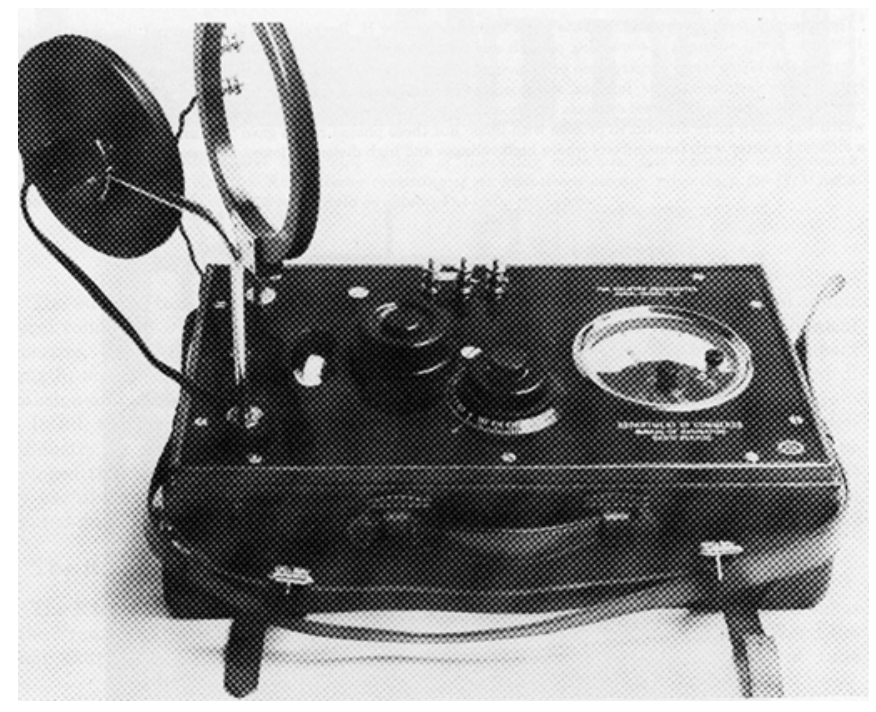

Fig. 4. NBS decremeter from 1912. 


\subsection{Radio Ban: The U.S. Enters World War I}

The entry of the United States into World War I in April 1917 brought the end of any form of radio transmission or reception by private parties in the United States, with the government shutting down or taking over all privately owned amateur and commercial transmitting stations and banning the use of receivers by the public. Only military or government stations were allowed on the air. The Radio Section responded to the war effort by making its laboratories and expertise available to solve the problems of wartime radio communications and working with the U.S. Army and Navy laboratories collocated at NBS. The section staff roster grew from 7 to 40 by the end of 1918, and a new building was constructed and dedicated to radio research. A list of research projects from the summer of 1918 includes writing training material and textbooks, aircraft location by radio, a radio direction finder system, and studies in antennas, radio-frequency (RF) insulating materials, and RF current measurements. Most of this work would continue after the war was over [1].

\section{WWV: The First Years}

After the war, the idea of broadcasting to the public began to catch on. The ban on privately owned and operated radio transmission and reception was finally lifted in 1919, and the broadcasting boom era began. The stage was set for WWV.

\subsection{Call Signs}

The call sign WWV was assigned to the Bureau of Standards Radio Section on October 1, 1919 [1]. Call signs were originally used in wire telegraphy to identify message origin and recipient offices along a common circuit [6]. Since the first radio stations were sending wireless telegraph messages, the practice continued. The Radio Act of 1912 formalized the use of call signs in the United States and legalized earlier international radio treaties. Commercial and government call signs were to be combinations of three (and later four) letters beginning with the letters $\mathrm{K}, \mathrm{N}$, and W. The letter $\mathrm{N}$ was reserved for U.S. Navy use, and certain combinations of call letters beginning with $\mathrm{W}$ were reserved for government use. WWV falls into this category. Amateur radio call signs were assigned using a different scheme. The call letters appear to have no particular meaning; in addition to WWV, early records show a WUP, WXY, and a WUQ as government radio stations operating in Washington, D.C. The records show that WUQ was the call sign of the U.S. Army Signal Corps station operating at NBS during this time [7].

Several dates have been put forward over the years as the "beginning" of WWV. William F. Snyder, co-author of Achievement in Radio (in many ways, the definitive history of radio research at NIST), points to March of 1920 as the point that "radio telephone broadcasts began" at the National Bureau of Standards [1]. The NBS Technical News Bulletin article "WWV's Golden Anniversary" refers to 1923 as the year that WWV began a regular schedule of frequency broadcasts [8]. Upon examination of the original (and very thorough) progress reports for the Radio Section from the early 1920s, no mention of the call letters could be found.

Perhaps this is due to the experimental nature of the work of the Radio Section in those days. Like many experiments, some of the equipment was assembled in a laboratory on a bench top, using materials available at the time; for instance, some inductors and coils were handmade on site. Other experimental broadcasts used off-the-shelf transmitting equipment. A view of the early Radio Section is shown in Fig. 5. 


\section{Journal of Research of the National Institute of Standards and Technology}

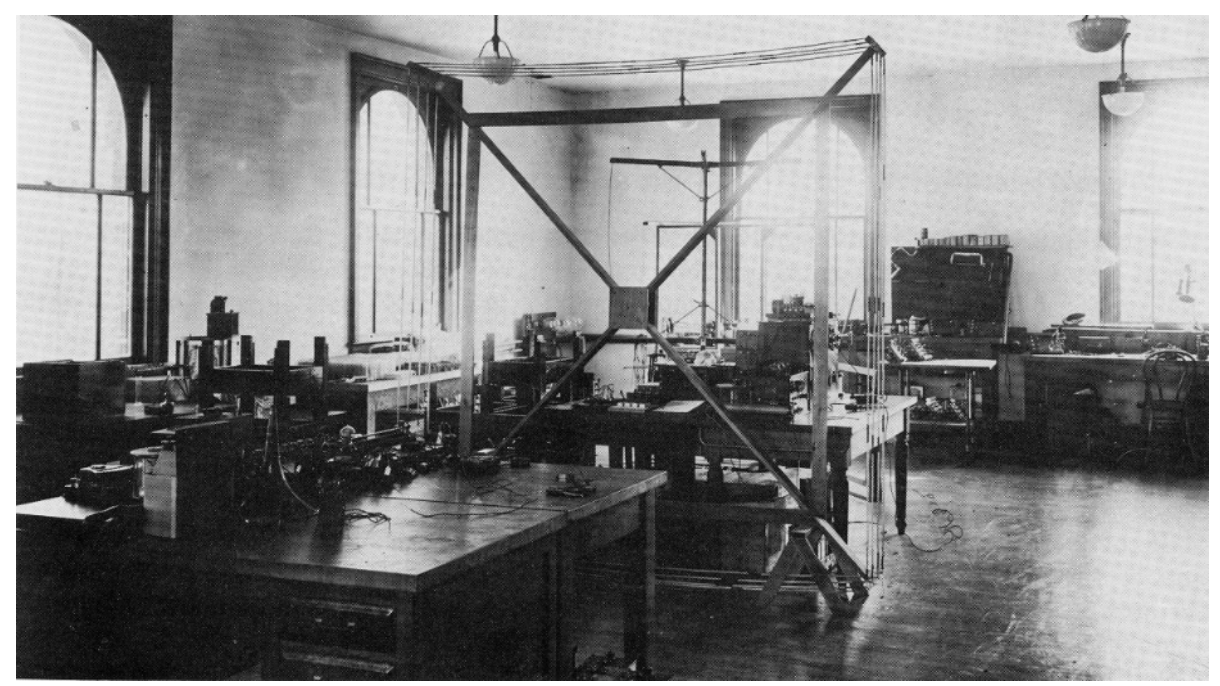

Fig. 5. Radio Section transmitting and receiving laboratory, 1920.

The "radio station" consisted of transmitters of various types and modes of operation, such as telegraphic code, connected to several different antennas [1]. In this context, the assignment of the call sign may have been viewed as merely a bureaucratic requirement, but the work of radio research using the "wireless apparatus" to transmit "wireless emissions" went on. The transmissions were sometimes unannounced, or only known to the intended recipient and often lasted only a few minutes. Music from a Victrola was sometimes chosen as the content, as well as telegraphic code [1].

The earliest known audio broadcast from NBS was chronicled not in the Radio Section records, but in a Washington newspaper. The Washington Times from February 26, 1919, declares the wonders of "music through the air," when popular tunes were played on a Victrola driving an early transmitter and broadcast several hundred yards to an NBS auditorium for the listening enjoyment of the audience. The writer states, "By this arrangement Washington merrymakers will soon be able to dance to the music made by an orchestra on one of New York's roof gardens” [9]. Although this demonstration may have been sponsored by the military laboratories then operating at NBS, Dellinger writes that the Radio Section conducted other experiments later in 1919 but before the call letters were granted, including "transmission experiments" to Johns Hopkins University in Baltimore, Maryland [10].

As 1920 began, the Radio Section was experimenting with Army Signal Corps transmitters for audio broadcasts and also starting construction of its own "radio-telephone" transmitter. The novelty of these early audio broadcasts is illustrated once again in a local newspaper, the Washington Evening Star of February 21, 1920, recounting the tale of one Harry B. Given, "listening in on general wireless messages" (probably telegraphic code) the previous evening on his amateur radio set when he was startled by the words "Hello there!" He turned to see who was in the room with him, only to discover that the words had come through his headphones. “The next thing he knew, John McCormack was singing 'Forgotten' in his room. Investigation disclosed the fact that the bureau of standards [sic], almost five miles [8 km] distant, was experimenting with a new wireless apparatus, which makes itself audible over the wireless receiving set” [11].

By May 1920, Dellinger writes that "experimental concerts are at present being sent out on Friday evenings from 8:30 to 11:00 by the Radio Laboratory...using a wavelength of 500 meters" (about 600 $\mathrm{kHz}$ ). These "concerts," thought to be the first scheduled broadcasts to a wide audience from WWV, were records being played on a Victrola with the output connected directly to the transmitter. The receiving range was initially about $40 \mathrm{~km}$ [1]. Figure 6 shows the Victrola with the transmitter built by the Radio Section. 


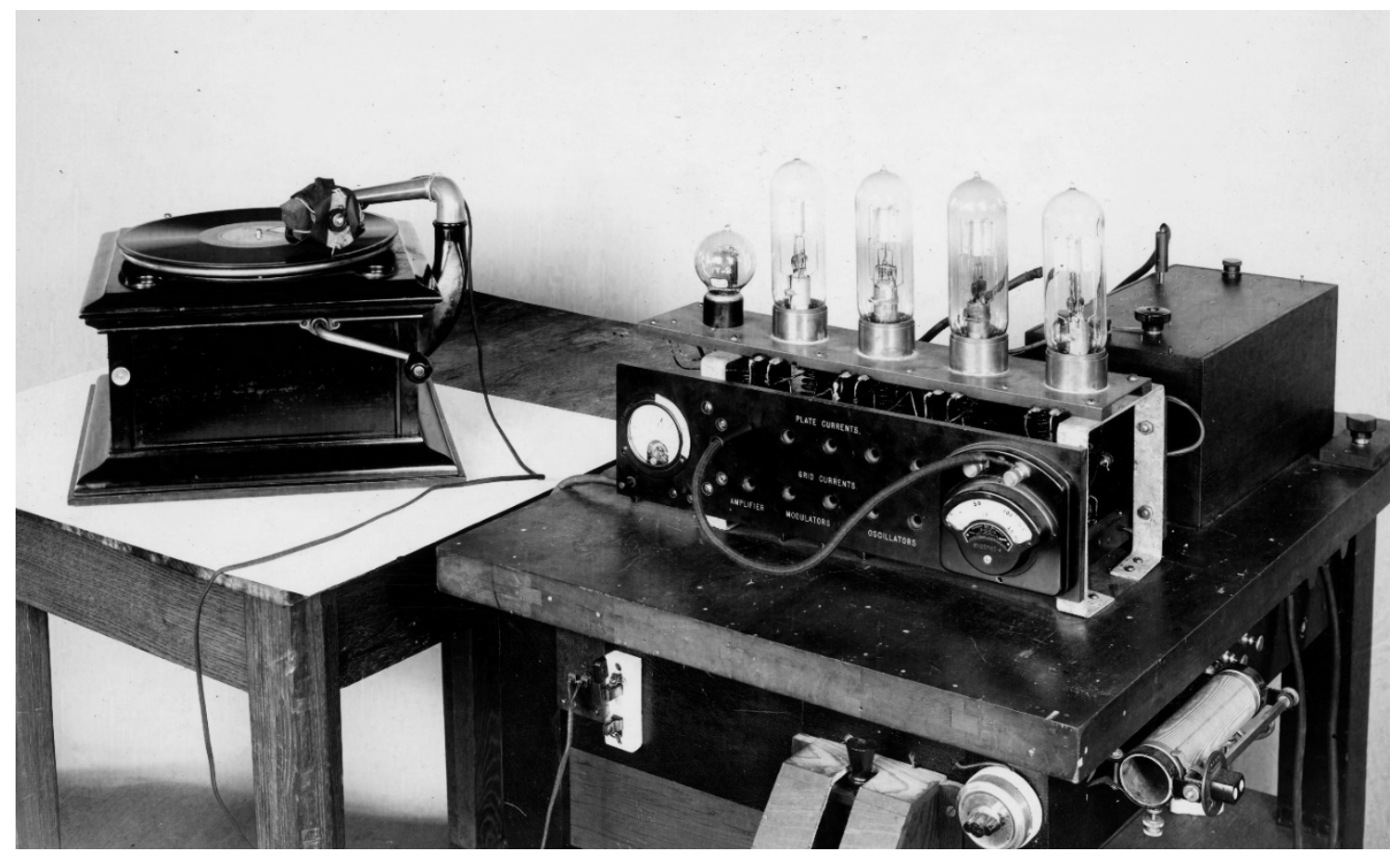

Fig. 6. NBS Victrola and transmitter used for “evening concerts,” 1920.

As the year drew to a close, WWV took the first tentative steps from an experiment to a service. The Radio Section was approached by the U.S. Department of Agriculture (USDA), which asked for assistance in disseminating market reports for the benefit of farmers. WWV was tasked with this effort, using a $2 \mathrm{~kW}$ spark gap transmitter and telegraphic code. This service began on December 15 and ran for 4 months on WWV; the broadcast consisted of a 600 word report provided by the USDA's Bureau of Markets, called the Daily Radio Marketgram. The program was later transferred to the Post Office Department for broadcast using their network of transmitters supporting the Air Mail Service. Interestingly, the USDA had been involved in radio research since 1900, primarily for the Weather Bureau, a part of the department at that time [12]. For sending market news, however, the Bureau of Markets turned to WWV.

\section{From Experiment to Infrastructure}

During the period from 1920 to 1923, the Radio Section continued the WWV experiment, working with "radiotelephony" to increase its range and explore its limitations using a variety of equipment. Dellinger became the section chief, and work progressed on other projects related to broadcasting, including development of new and improved receivers. A portable receiver called the "Portaphone" was built in the summer of 1921, complete with a "morning glory" horn speaker. Figure 7 shows the Portaphone in use. 


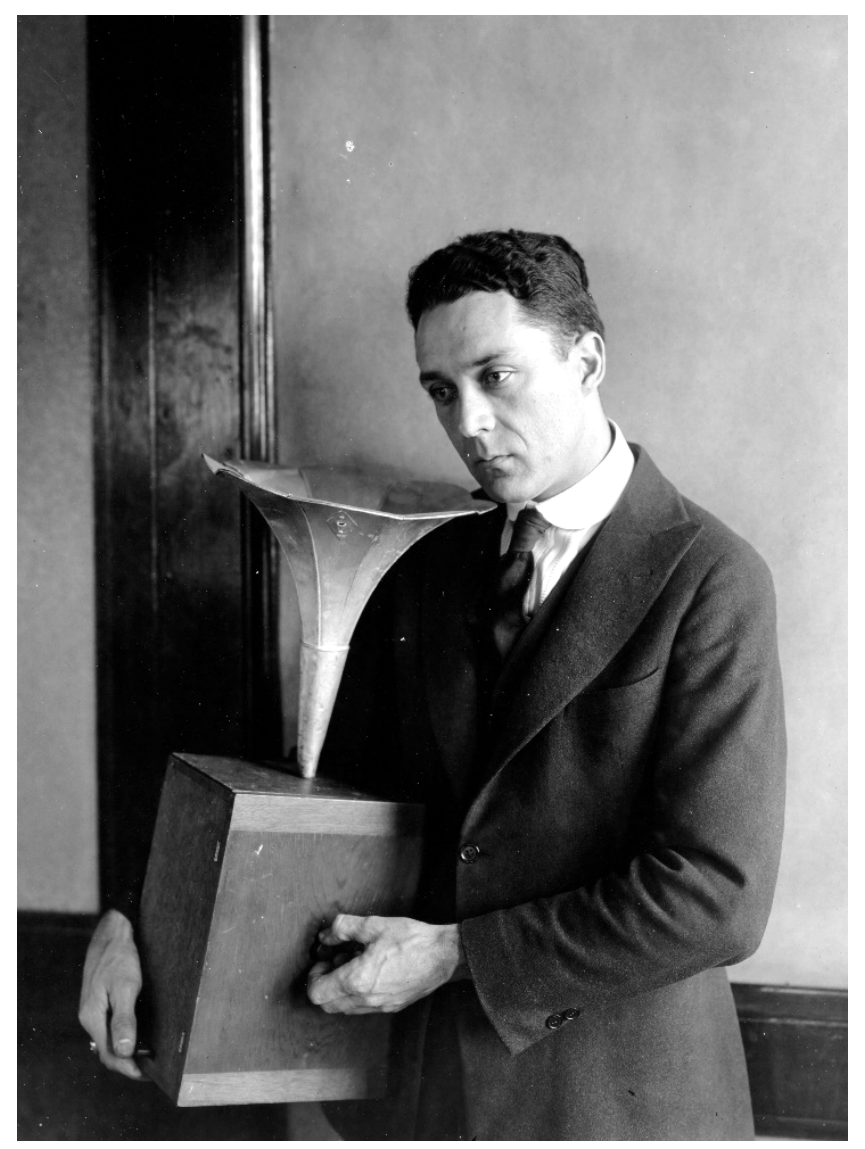

Fig. 7. Portaphone portable receiver, 1921.

A notable achievement was developing a receiver that worked on ordinary "house current” $(60 \mathrm{~Hz}$ alternating current $[\mathrm{AC}]$ ) rather than expensive and bulky batteries, as had been the norm. Another first was a system of radio remote control, the "radio receiving relay," developed by section staffer Francis Dunmore. Other crucial work on characterizing vacuum tubes, airplane navigation, textbooks, and development of test and calibration equipment and procedures continued [1].

As the Radio Section continued its research work into 1920s, the radio boom expanded in the United States. By the end of 1922, about 570 commercial radio stations were broadcasting in a frequency band of $1000 \mathrm{kHz}$, and many were having a great deal of difficulty staying on their assigned frequency. In addition, the many new receivers on the market had to be able to "tune" to the assigned frequency of the station the listener wanted to hear, so the tuning dial had to be calibrated to the actual frequencies being broadcasted. Dellinger stated the issues faced at the time in an article titled "Reducing the Guesswork in Tuning":

The waves used by the broadcasting stations are spaced 10 kilocycles apart ( 3 meters at a wavelength of 300 meters). Thus one station is on 990 kilocycles, another on 1000 , and another on 1,010 kilocycles. A variation of the frequency of 1 per cent, for example, would be a variation of 10 kilocycles and could cause one station to be using exactly the wave that had been assigned to another. The whole success of American broadcasting is thus tied up with the placing of broadcasting stations on the correct frequencies to an accuracy approaching 99.9 per cent. Since receiving sets are now available by which an individual can hear the stations from all over the United States on the same night, the importance of this accuracy is apparent. [13] 
As a standards organization, NBS was responsible for disseminating the means for compliance to the accuracy the new technology demanded. Although the Radio Section had been calibrating instruments for checking station frequencies, the demand had become overwhelming. A new solution was required that would provide a readily accessible means of calibrating transmitters and receivers quickly and accurately. In December 1922, the monthly report of the Radio Section states: "A conference of members of the staff was held regarding the proposed transmission of standard wave length signals. It was decided to transmit such signals as soon as possible, and is expected that preliminary tests will be started early in January” [14]. These tests were conducted, and a new antenna was installed at the Radio Building on the NBS grounds. The Department of Commerce Radio Service Bulletin February 1, 1923, issue announced that the first scheduled broadcast of standard frequencies on WWV would take place on March 6. To avoid interference from commercial stations, the broadcasts would begin at 11:00 p.m. and run until 1:15 a.m., local time, on several frequencies between 550 and 1500 meters (545 and $200 \mathrm{kHz}$ ), using a four-tube transmitter designed by the Radio Section. The broadcasts continued, usually on a weekly schedule announced with a press release. A typical broadcast consisted of an announcement in code and voice repeated "QST de WWV Standard Wave Signals," followed by an announcement of the wavelength of the signal. The broadcast was interrupted briefly to allow the transmitter to be reconfigured for a different frequency. Published accuracy was "better than three-tenths of one percent.” By June, biweekly transmissions were taking place in a frequency range from $75 \mathrm{kHz}$ to $2000 \mathrm{kHz}$. The coverage range was about $1600 \mathrm{~km}$. Figure 8 shows a view of the Radio Section building in 1923. The larger "flat-top" antenna on the right was used for broadcast frequencies below $300 \mathrm{kHz}$, and the smaller T-shaped cage antenna on the left was used for frequencies above $300 \mathrm{kHz}$ [1].

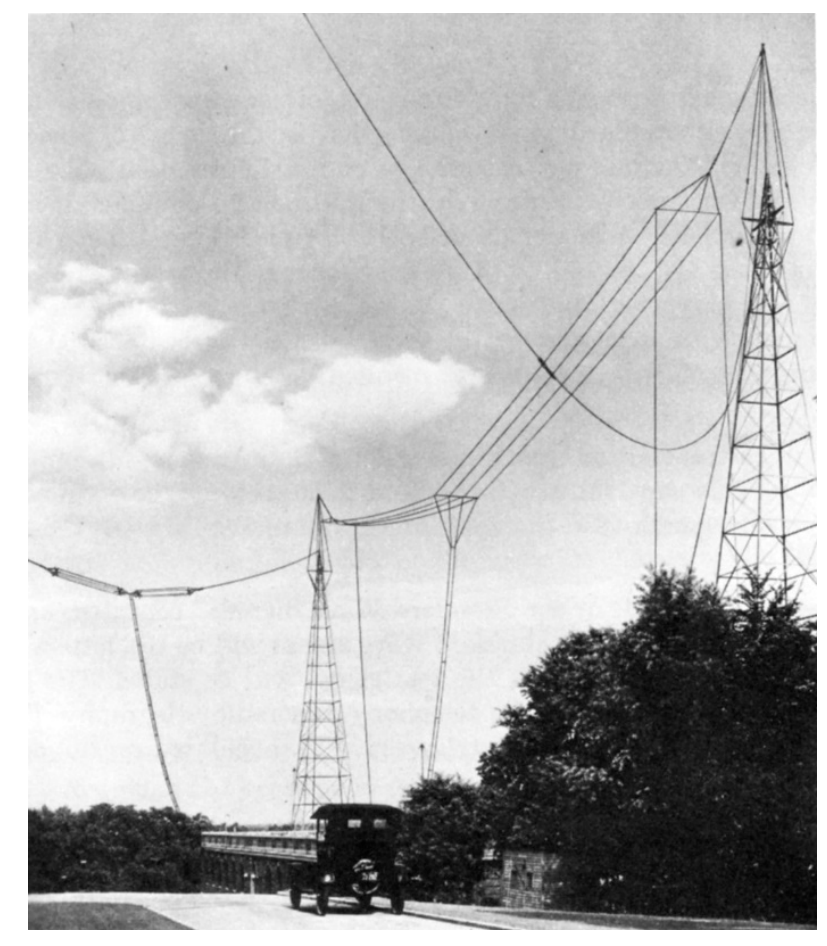

Fig. 8. Radio Section building with antennas, 1923.

As the broadcasts continued through the following year, the amateur radio journal QST offered an enthusiastic summary of the effect they were having:

Probably no radio station has ever rendered the American radio world so great a service as WWV in transmitting the standard wave signals. Before these signals began both broadcast and amateur waves were uncertain and often wavemeters disagreed violently. Since the signals began those in the East have been able to make precision calibration on their own wavemeters and pass the information on to the west. [15] 
The phrase "pass the information on to the west" indicated the WWV signal could not reach the western part of the country reliably.

The Radio Section had developed relationships with universities as time passed, as a resource for texts and for its pioneering research, as well as promoting radio research at the schools [16]. Collaboration with several institutions was pursued; the transmissions to Johns Hopkins University in Baltimore, Maryland, are an example. This collaboration was encouraged from the highest levels; Department of Commerce Secretary Herbert Hoover had at one time envisioned an interuniversity radio network across the country and had set aside the 1290 meter band (230 to $235 \mathrm{kHz}$ ) for U.S. educational institutions [17].

It seems that at least one result of this collaboration was the use of Stanford University's radio station 6XBM in Palo Alto, California, as a west coast "standard wave" station. Originally licensed in November 1922 as KFGH, the station was initially used to broadcast athletic events and faculty talks. Stanford Professor H. H. Henline had it relicensed as experimental station 6XBM, as part of the newly founded Stanford Communications Laboratory [17]. Radio Section staffer Hoy J. Walls, who designed and built the WWV transmitter, visited Stanford in 1924 to help set up the equipment there [18]. Three methods for cross-checking the accuracy of the signals were devised, and the station began broadcasting standard wave frequencies in September 1924, using two $250 \mathrm{~W}$ vacuum tubes borrowed from Stanford undergraduate Herbert Hoover, Jr., until tubes supplied by NBS were obtained [17]. The broadcasts were on the same biweekly frequency schedule with the same accuracy as WWV and continued until June 1926. The university provided the service voluntarily, and although some parts and equipment were provided by NBS, it was never paid to provide the service [1].

The attempts to expand coverage of the WWV signals led to other cooperative efforts, with radio stations operated by the Massachusetts Institute of Technology in Cambridge, Massachusetts, and even the Gold Medal Flour Co. in Minneapolis, Minnesota. Other collaborations followed. These efforts, along with the availability of better wavemeters and especially the advent of piezoelectric quartz oscillators, meant that some stations that were monitored by the Radio Section were accurate enough to be utilized as frequency references [19]. This led NBS in 1926 to consider discontinuing operating WWV for the dissemination of standard frequencies. However, the overwhelming negative response to this idea from many institutions, amateurs, and individuals convinced NBS to continue the broadcasts [1].

\section{Frequency Standards at NBS}

The ability of radio transmitters and receivers to work properly can be directly related to the frequency standards upon which they are based. The first radio frequency standards used in the Radio Section were wavemeters, instruments that consisted of variable capacitors and interchangeable standard inductors. However, the accuracy of these instruments was typically no better than 1 part in 100 in 1920 . As the need for more accurate standards became apparent, the standard wavemeters used by NBS were refined, and other approaches were explored for meeting this need, including high-frequency alternators, electrically driven tuning forks, and measurement of high-frequency standing waves on parallel wires. Some progress was made, but as the end of the 1920s approached, accuracy of frequency measurements was still around 1 part in 1000. New rules tightening the requirements for commercial radio stations to stay on their assigned frequency demanded new methods and new technology.

The answer was found with quartz crystal oscillators. The development of piezoelectric quartz crystals as frequency standards at NBS began in 1920, and, by the middle of the decade, portable units were in use by radio inspectors in the field. A quartz oscillator was first used to control a WWV frequency in 1927, and by late 1929, four $100 \mathrm{kHz}$ quartz oscillators made up the newly named National Primary Standard of Radio Frequency, with an accuracy of about 1 part in $10^{7}$ [1]. One of the quartz oscillators in its temperature-controlled cabinet is shown in Fig. 9. 


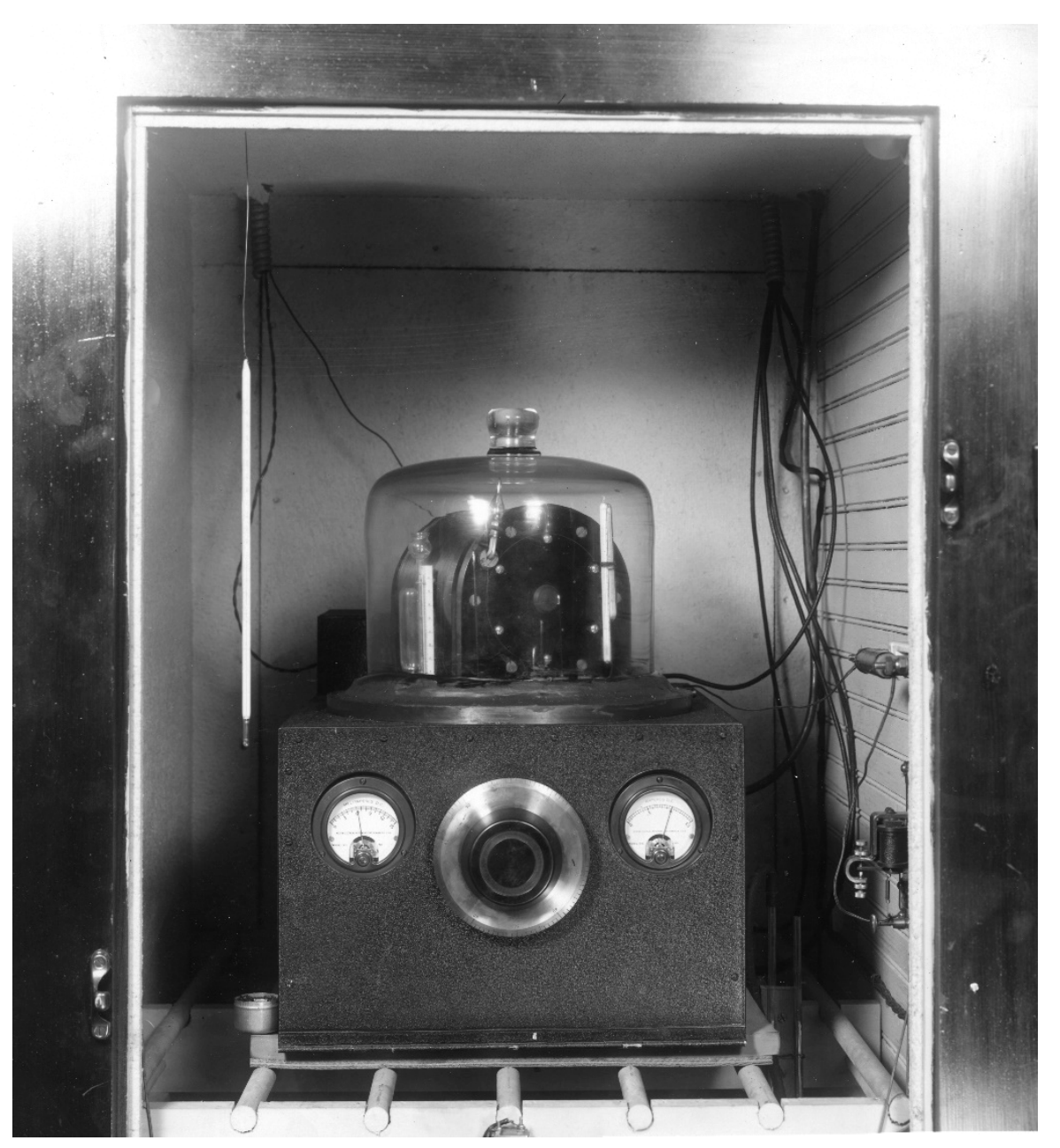

Fig. 9. One of the four $100 \mathrm{kHz}$ quartz oscillators that made up the National Primary Standard of Radio Frequency.

\section{Amateur Activity in the 1920s}

The Radio Act of 1912 had confined amateurs to one band $(200 \mathrm{~m})$ and required licensing, but the wideband noise of primitive spark gap transmitters continued across the spectrum. Soon afterwards, a movement arose among amateurs to police themselves. In 1914, the American Radio Relay League (ARRL) was founded to coordinate the sending of amateur wireless messages over long distances by relaying them from station to station. The journal of the league, QST, soon followed, and hams began to work together to limit interference and promote good engineering and operating practices. While the Department of Commerce was responsible for enforcing the rules for amateurs and commercial stations alike, the Radio Section also offered helpful advice and resources for the hams. Letter Circulars were written with amateurs in mind, with drawings and plans of the latest equipment designs [20]. Of course, the WWV standard frequency broadcasts were invaluable to hams for calibrating their equipment and complying with the regulations.

In 1920, a cooperative effort was set up between the Radio Section and the ARRL to perform a series of tests, using amateur stations in the Northeast and Midwest United States to explore the phenomenon of signal fading. These tests used several amateur radio stations operating on a specific schedule as a signal source, and reception reports were gathered over a large area. The tests started on June 1 and ran until midJuly. The results were encouraging, and the data were useful. Further tests were conducted the following 
October, January, and April. The April test used the WWV transmitter as well. A Radio Section staff member, Robert S. Kruse, coordinated the tests with the ARRL. Radio Section reports show the tests were deemed a success, and the data from them were collated and analyzed. Letter Circulars and papers were written about the results [21]. These tests were the beginning of decades of research on the effects of the ionosphere on radio-signal propagation [1].

The close cooperation between the ARRL and NBS can in part be attributed to the number of hams who worked for the Radio Section, including Kruse (call sign W1BAO), who later left NBS to work for QST as a technical editor. Over the decades since, many NBS and NIST staffers have held amateur radio licenses, down to the present day, as several WWV staff members are hams.

\section{The 1930s: New Facilities, New Format, New Schedules}

As the 1930s approached, the need for a separate facility for WWV became more pressing. The station was now viewed by the public, institutions, and NBS as an important part of the nation's infrastructure, and the time had come to invest in its future. The $1 \mathrm{~kW}$ transmitter that had carried the service for nearly 8 years was becoming obsolete, and the demands of regularly scheduled radio broadcasts began to disrupt other projects at the NBS. NBS owned several field sites in the area surrounding Washington, D.C. Initially, a site in College Park, Maryland, northeast of Washington, D.C., which was used for airplane navigation projects, was chosen as the new location for WWV. A $150 \mathrm{~W}$ transmitter operating on $5 \mathrm{MHz}$ was constructed and put in operation in January 1931; by 1932, the power had been increased to $1 \mathrm{~kW}$. Frequency accuracy of the broadcast was better than 2 parts in $10^{7}$, monitored from the NBS laboratories in Washington, D.C. [1]. However, the proximity of the site to an airport limited the height of the transmitting antennas, and, in December 1932, WWV was moved again to a 10 hectare (25 acre) site on the Experimental Farm of the USDA in Beltsville, Maryland, about $21 \mathrm{~km}$ northeast of the NBS grounds. A wood-framed building was used to house the transmitters and the standard frequency equipment. In April of the following year, a water-cooled $30 \mathrm{~kW}$ transmitter of the latest design was purchased and put in operation. The transmitter operated initially on $5 \mathrm{MHz}$, and, in February 1935, $10 \mathrm{MHz}$ and $15 \mathrm{MHz}$ frequencies were added at $20 \mathrm{~kW}$. Half-wave horizontal doublet antennas for each frequency were suspended from $20 \mathrm{~m}$ high poles, fed by $600 \mathrm{ohm}$ matched-impedance transmission lines [22]. At first, transmissions occurred only on Tuesdays for $4 \mathrm{~h}$, and as time passed, the broadcast schedule was expanded. The June 1936 issue of QST lists the schedule at that time:

Each Tuesday, Wednesday and Friday (except legal holidays), the National Bureau of Standards station WWV will transmit on three frequencies as follows: noon to 1:00 p.m. E.S.T., 15,000 kc; 1:15 to 2:15 p.m., 10,000 kc; 2:30 to 3:30 p.m., 5000 kc. On each Tuesday and Friday, the emissions are continuous unmodulated waves (c.w.); and on each Wednesday they are modulated by an audio frequency. The audio frequency is in general 1000 cycles per second. [23]

The audio tone was added in October 1935. While this schedule may sound complicated, it was much simpler than the multiple frequencies and times of day (actually, night) broadcast by WWV previously. The additional power from the new equipment meant the broadcasts could potentially be received during the daytime on at least one frequency throughout the United States. A photo of the main transmitter building in Fig. 10 accentuates the antenna cables. 


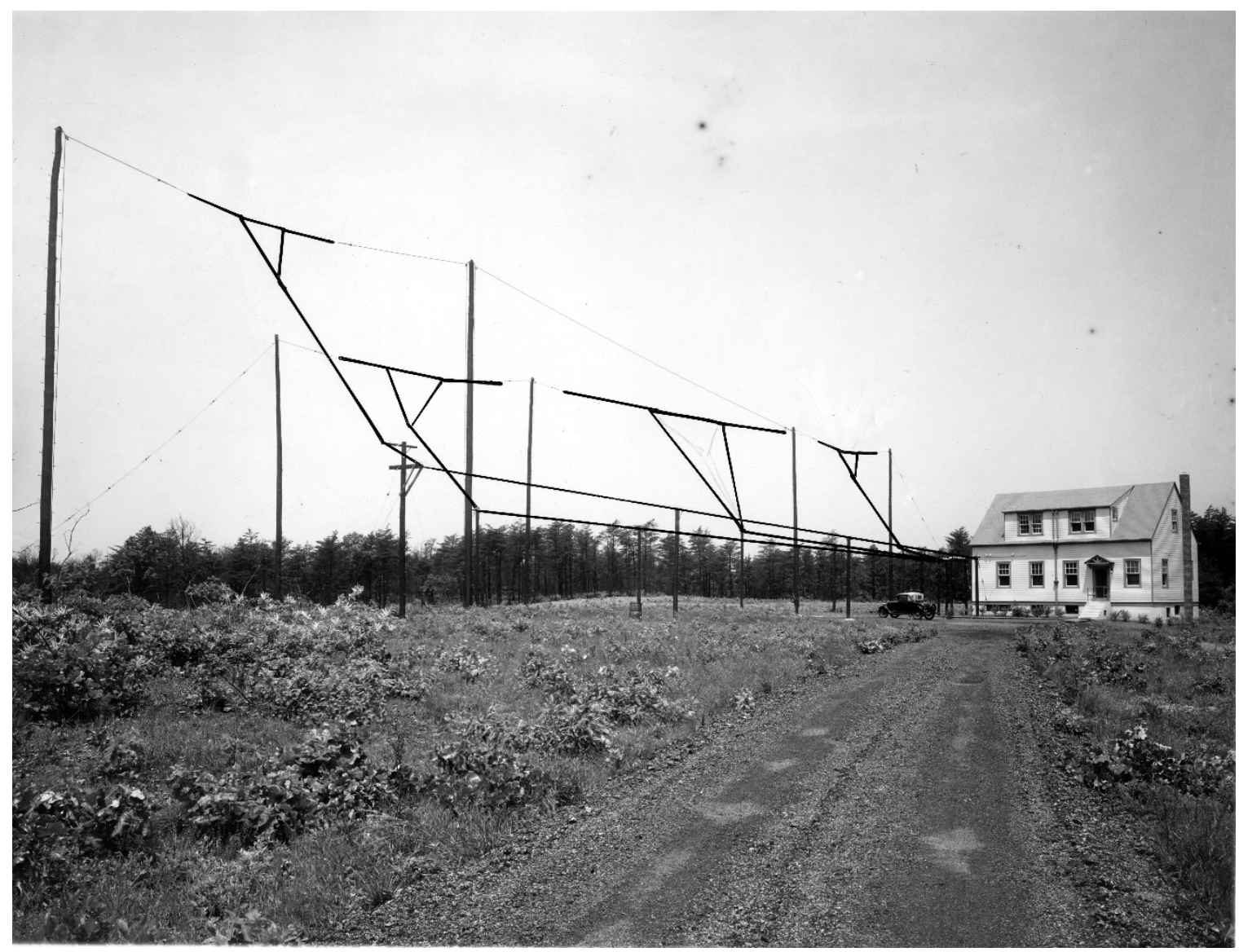

Fig. 10. WWV main transmitter building, Beltsville, Maryland, 1933.

Additions to the WWV broadcasts in the 1930s included the $1000 \mathrm{~Hz}$ modulated tone already mentioned, and a tone at $440 \mathrm{~Hz}$, the musical note A above middle C, in August 1936. This service was provided at the request of several musical organizations and was first broadcast over the NBC radio network. The tone, generated at the NBS laboratories, was connected to the network over a landline and aired as a feature of a musical variety program on August 26, along with an explanation of the purpose of the new service from WWV, which commenced a few days later [1].

In June 1937, seconds pulses 5 ms long were added to the broadcast, as well as an announcement of current ionospheric conditions on Wednesday broadcasts. An audio voice announcement of station identification was included in the broadcast; this and other announcements were recorded on phonograph records using equipment at NBS. The $15 \mathrm{MHz}$ frequency was temporarily replaced with $20 \mathrm{MHz}$ until May 1940.

Accuracy of the standard frequency broadcasts from Beltsville during the 1930s was better than 2 parts in $10^{7}$, and typically 4 parts in $10^{8}$, using on-site crystal oscillators [1].

\subsection{Other Radio Research}

Other radio research projects in the 1930s included a study on the feasibility of nationwide coverage of reliable voice transmissions from the Washington, D.C., area, performed for the Federal Bureau of Investigation (FBI) in 1935. Another project from within NBS was the attempt by Radio Section scientist W. D. George to reflect $20 \mathrm{MHz}$ signals from a WWV transmitter off the moon. The unsuccessful 
experiment performed over $2 \mathrm{~d}$ in 1939 nevertheless indicates the spirit of innovation at the Radio Section [1].

\section{The 1940s}

Disaster struck WWV in 1940. On the morning of November 6, a fire broke out in the wooden transmitter building. A local newspaper article had the details: “A watchman...noticed smoke coming from the attic of the building at 6:30 a.m. Firemen... were forced to stretch hose lines almost half a mile to reach the nearest hydrant" and then had to battle high winds. By the time water was available, the building was almost completely consumed. The blaze also started a forest fire in the nearby woods, which firefighters fought for $4 \mathrm{~h}$. "SIGNED OFF-No more signals will be heard from this transmitter station" blared the caption of the front-page photo of the wreckage, shown in Fig. 11 [24].

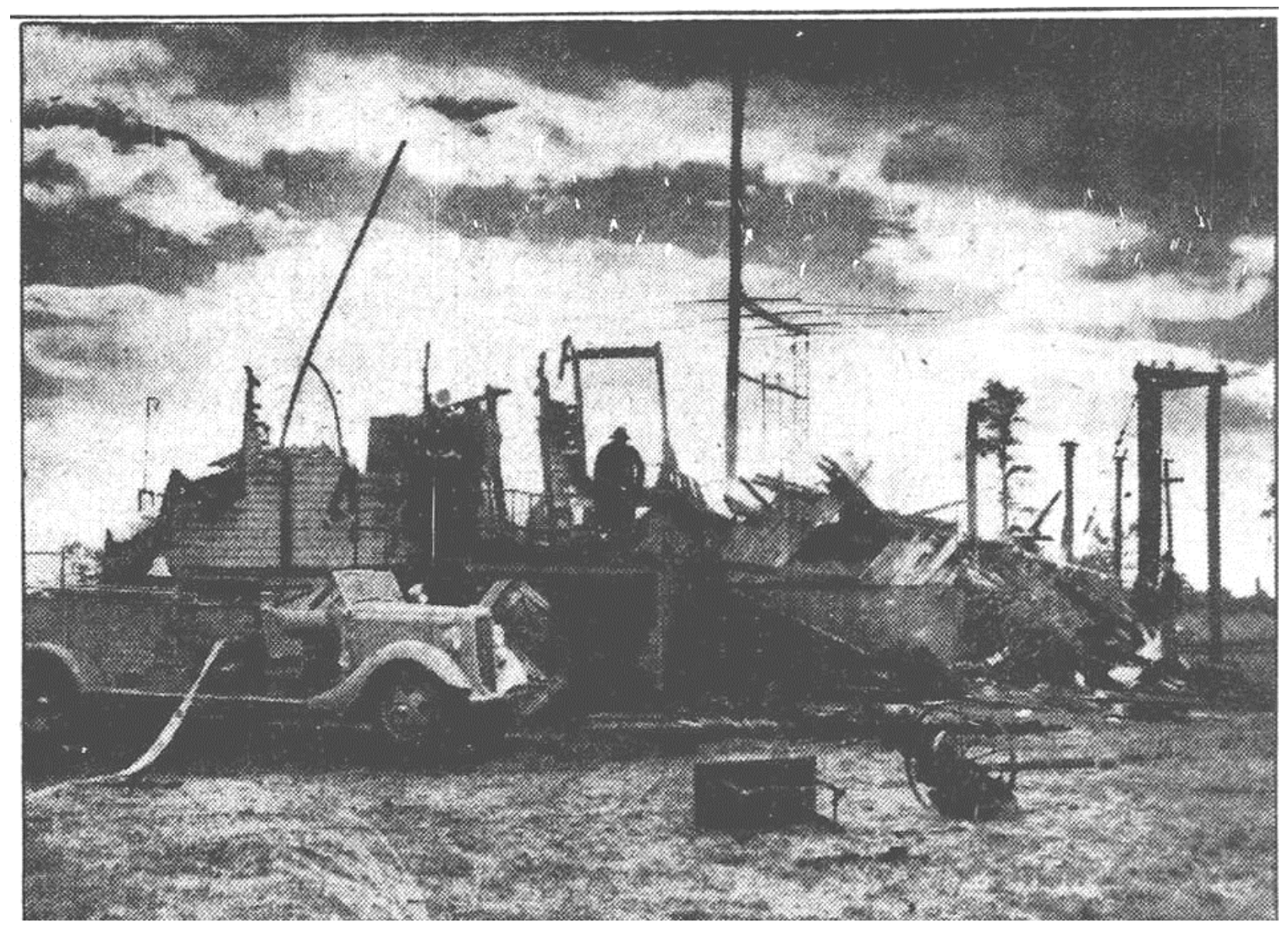

Fig. 11. WWV transmitter building after the fire, November 6, 1940.

However, the fire did not entirely destroy WWV. The standard frequency equipment, which operated in the basement of the transmitter building was salvaged and put back in service in an adjacent building, along with a $1 \mathrm{~kW}$ transmitter already installed there. With this arrangement, WWV was back on the air at $5 \mathrm{MHz}$ without loss of accuracy of the standard frequency on November 11, just $5 \mathrm{~d}$ after the fire. However, voice announcements, seconds pulses, and the audio tones were not immediately available, nor were any other carrier frequencies.

A news release 4 months later gives an update on the service: the single broadcast frequency, $5 \mathrm{MHz}$ at $1 \mathrm{~kW}$, would now be operated continuously. The $440 \mathrm{~Hz}$ tone and seconds pulses were restored (but not the $1 \mathrm{kHz}$ tone). The $440 \mathrm{~Hz}$ tone was omitted every fifth minute to allow the station identification to be sent out in telegraphic code. The time intervals between identification announcements were reported by NBS, 
"so synchronized with the basic time service of the U.S. Naval Observatory that they mark accurately the hour and successive 5-minute periods.” The news release went on to assure users that,

The service from the temporary transmitter will continue for some months. As rapidly as possible the Bureau will establish a new station to provide more fully than in the past, standard frequencies reliably receivable at all times throughout the country. [25]

Congress agreed: an act passed in July 1941 provided US\$230,000 for new station facilities. In August, a new site was selected about $5 \mathrm{~km}$ south of the old one, although the Beltsville address was retained. It is notable that no technical description of the new station facilities and equipment was published. Whether due to wartime security requirements, a lack of personnel, or some other reason, documentation on the new WWV facility is scant. However, a number of photographs were taken, many more than previous installations. The transmitter building was a spacious brick structure located at the top of a slight rise. Figure 12 is a rare color photo of the station from the entrance road.

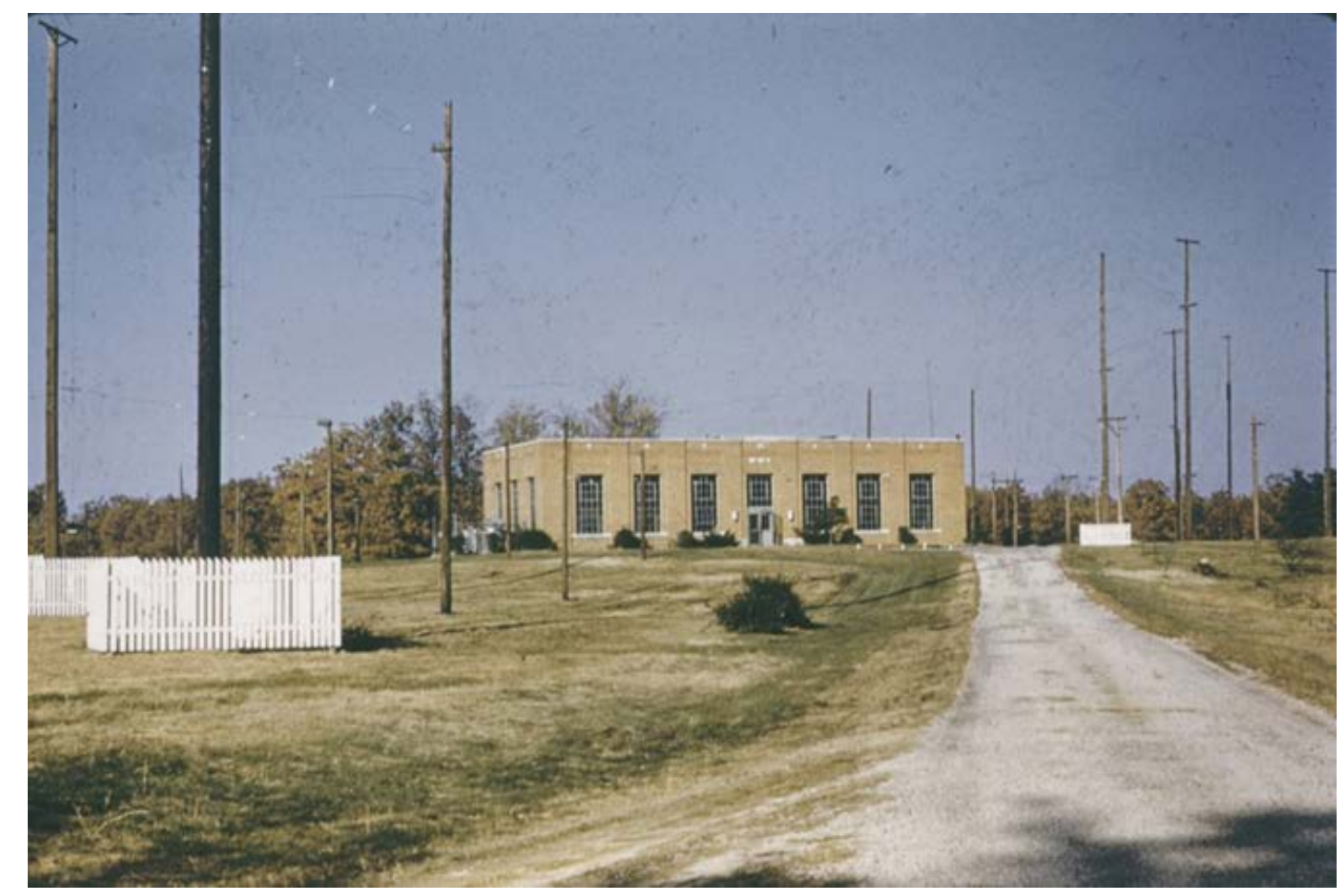

Fig. 12. WWV site, Beltsville, Maryland.

Antennas for each frequency were erected around the building in the surrounding antenna field, some on poles brought in from forests in Oregon; the three tallest poles were $35 \mathrm{~m}$ long before installation. The half-wave vertical dipole antennas were made of cables suspended from crossbars at the tops of the poles, anchored to concrete blocks in the ground. Ceramic insulators were used to isolate the antennas from the poles and blocks. All antennas had omnidirectional radiation patterns [26, 27]. The white fences enclosed the lower part of the vertical antennas for safety. Figure 13 shows a view of the transmitter building, with one of the dipole antennas in the foreground. 


\section{Journal of Research of the National Institute of Standards and Technology}

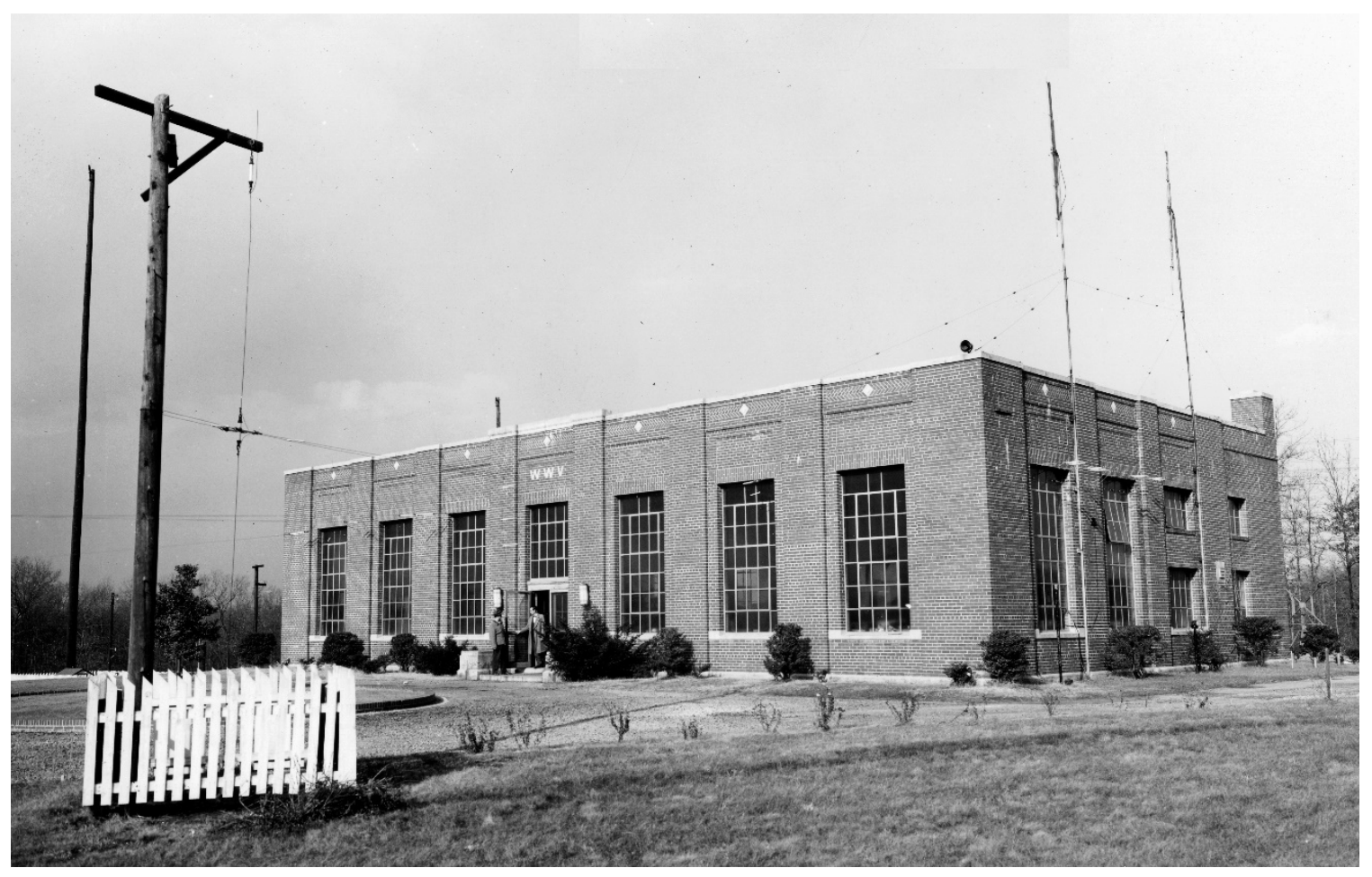

Fig. 13. WWV building, with dipole antenna on the left.

The building was occupied in January 1943. Broadcasts began at that time using lower powered transmitters until the installation of new, higher powered equipment was completed in August, at which time WWV began operating continuously on $5 \mathrm{MHz}$ and $10 \mathrm{MHz}$, with daytime operation on $15 \mathrm{MHz}$. Audio tones were broadcast at $440 \mathrm{~Hz}$ and $4 \mathrm{kHz}$ concurrently, and ticks each second were included. The 5 min time intervals continued to be synchronized with the basic time service of the U.S. Naval Observatory (USNO). Station identification voice announcements were added at the hour and half-hour. Standard frequency was supplied by three $100 \mathrm{kHz}$ quartz crystal oscillators placed in a concrete vault about $8 \mathrm{~m}$ below ground level, where the nearly constant temperature and humidity contributed to their stability, and the output of each oscillator could be connected remotely. Reliable reception was claimed "in general...at all times throughout the United States and North Atlantic Ocean, and fair reception over most of the world” [28]. The interior of the transmitter building is shown in Fig. 14. 


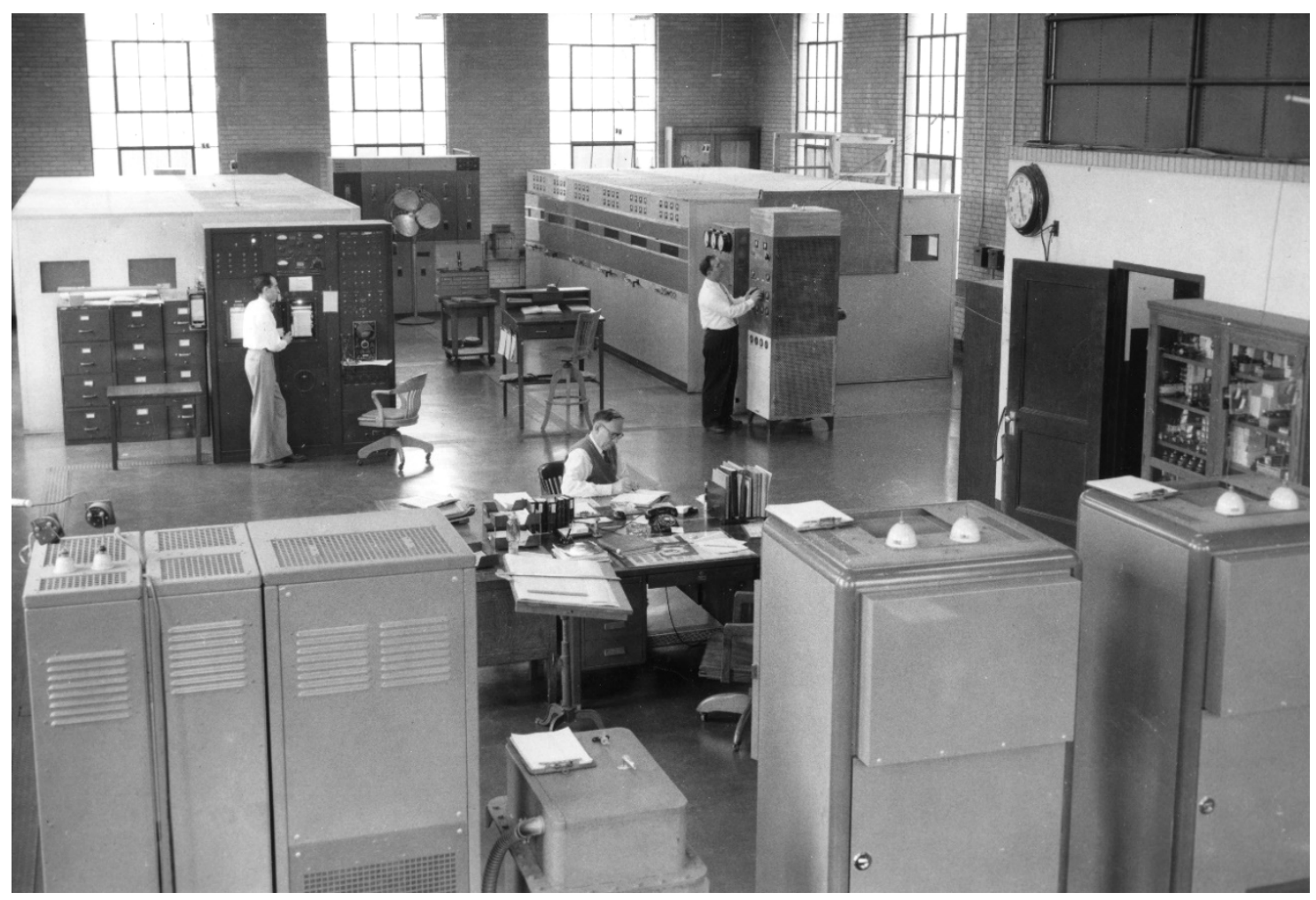

Fig. 14. Interior view of the new WWV building.

More service enhancements were soon added. On February 1, 1944, a 2.5 MHz broadcast frequency was added to WWV, operating from 7:00 p.m. to 9:00 a.m. local time and intended to serve the region around Washington, D.C. Unlike the other broadcast frequencies, the transmitter was connected to a quarter-wave vertical antenna. Another new feature was the omission of seconds pulses from the 59th second of every minute, creating a 1 min time interval.

Perhaps the most momentous change for many users of the WWV broadcasts occurred in June 1944, when the superintendent of the USNO authorized the synchronization of the WWV time signals with those of the USNO. The synchronization had been made previously in that the hour, half-hour, and 5 min intervals were "on-time” with respect to USNO's basic time service, but the time of day was not announced. On October 2, 1945, the station began broadcasting time announcements in telegraphic code, using automated equipment.

In January 1946, WWV began broadcasting propagation disturbance warnings automatically using telegraphic code at half-hour intervals. In December of that year, broadcasts resumed on $20 \mathrm{MHz}$ and added on 25, 30, and $35 \mathrm{MHz}$, and the transmitted accuracy of the signals was 2 parts in $10^{8}$. The 30 and 35 MHz signals were discontinued in January 1953.

Also in 1946, the Radio Section was reorganized as part of the Central Radio Propagation Laboratory (CRPL) at NBS, with Dellinger as chief. Two years later, Dr. Dellinger retired, after nearly 40 years of government service.

On November 22, 1948, Radio Station WWVH began operations at Kihei, on the island of Maui, Hawaii, in order to provide improved standard frequency coverage for the Pacific region. Services on 5 $\mathrm{MHz}, 10 \mathrm{MHz}$, and $15 \mathrm{MHz}$ included a $440 \mathrm{~Hz}$ tone and $1 \mathrm{~s}$ pulses. Agreement with the WWV broadcasts was better than 2 parts in $10^{8}$. This "sister station" to WWV continued operating on Maui until 1971, when it was moved to new facilities at Kekaha on the island of Kauai. It remains in operation there to this day [1]. 


\section{The 1950s}

Although WWV was now firmly established as a resource, changes to the broadcasts continued in the 1950 s in an attempt to make them even more useful. On January 1, 1950, time of day voice announcements began running every $5 \mathrm{~min}$, and the $4 \mathrm{kHz}$ standard audio frequency was replaced by a $600 \mathrm{~Hz}$ tone. Twelve-hour ionospheric condition forecasts of North Atlantic transmission paths began in July 1952. In January 1953, the 30 and $35 \mathrm{MHz}$ broadcasts were shut down [1].

In 1954, CRPL was moved to the new NBS Boulder Laboratories complex in Colorado, along with the four crystal oscillators of the National Primary Frequency and Time Standard [1]. Later in the decade, the WWV signal was used in comparisons by USNO in Washington, D.C., and the National Physical Laboratory (NPL) in Teddington, UK. USNO compared WWV against an astronomical time scale (UT2). Simultaneously, NPL compared the same WWV signal against their newly developed cesium frequency standard. Data from these "common-view" measurements allowed the laboratories to compare the lengths of the astronomical and atomic seconds, which was key research used in redefining the second in the next decade [29]. NBS was developing its own cesium standard known as NBS-1, and WWV comparisons with this new frequency standard began in December 1957 [27].

Another enhancement to the broadcasts in the 1950s was the implementation of a $40 \mathrm{~ms}$ period in each second of the broadcasts to allow the seconds pulse or "tick," consisting of five cycles of a $1000 \mathrm{~Hz}$ tone to be heard clearly. Each 5 ms tick was preceded by 10 ms of silence (no audio tone or other sound) and followed by another $25 \mathrm{~ms}$ silent period. The beginning of the pulse represented the on-time marker (OTM), that is, the beginning of that second. Also in 1954, WWV began broadcasting standard audio frequencies on only the upper sidebands of all frequencies except $25 \mathrm{MHz}$. This practice continued until December 1966, when all audio tones were restored to both sidebands.

The 1950s brought on a spirit of collaboration and cooperation in the scientific community in spite of political and military tensions throughout the world. The International Geophysical Year (IGY) was designated as the period from July 1, 1957, to December 31, 1958. WWV's contributions to the wideranging international scientific project included the first geophysical alert on the broadcasts (descriptions of solar terrestrial conditions, used in predicting high-frequency [HF] radio propagation over long distances) and other messages to IGY projects throughout the world. The alerts and messages were in telegraphic code [1].

By the end of the decade, improvements in the frequency standard equipment at NBS and WWV allowed an accuracy of 1 part in $10^{9}$ as transmitted. However, monitoring of the WWV broadcasts from the CRPL laboratories in Boulder, Colorado, illustrated the effects of ionospheric disturbances in the form of timing errors of up to 4 parts in $10^{8}$ at times. It was known that low-frequency (LF) broadcasts were less affected by these disturbances, and in response, experimental station KK2XEI went on the air in 1956 with a $60 \mathrm{kHz}$ carrier frequency controlled by a cesium frequency standard on the campus of the Boulder Laboratories. The $2 \mathrm{~kW}$ transmitter radiated less than $2 \mathrm{~W}$ from the electrically small antenna on the Boulder campus, but the signal was received and monitored at Harvard University in Cambridge, Massachusetts. After several years of testing, the experimental station was issued the call sign WWVB. Exploration of very low frequency (VLF) standard frequency broadcasts was advanced in 1960, when another NBS station called WWVL broadcasting at $20 \mathrm{kHz}$ began operation in a canyon near Boulder [30].

\section{The 1960s: The High Point}

The 1960s can be viewed as the high point of WWV's popularity; the broadcasts were known and used by government, military, research organizations, and individuals worldwide. The shortwave bands were being fully exploited for their tremendous range; at the same time, their limitations with regard to accurate time and frequency signals were by now well known. CRPL continued to work with WWV to enhance the broadcasts to the greatest extent with the resources and technology at hand. In April 1960, the first time code was placed on the WWV broadcasts. Developed in collaboration with a number of organizations, it was known as the National Aeronautics and Space Administration (NASA) 36 bit time code, after one of the main contributors to its development. The binary coded decimal (BCD) code contained seconds, minutes, hours, and day-of-year information broadcast 10 times per hour, and it is believed to be the first 
digital time code available by radio in the United States. This technology allowed the development of selfsetting radio-controlled clocks for the first time. The following January, the location name of the station was changed from Beltsville to Greenbelt, Maryland [29, 31].

\section{New Directions: WWVB and WWVL}

To address the need for frequency signals with accuracy greater than what WWV could provide, NBS began construction of a permanent home for WWVB and WWVL. A suitable location was found north of Fort Collins, Colorado. The 154 hectare (380 acre) site was attractive due to the high conductivity of the alkaline soil and the increased distance from the Rocky Mountains, which had attenuated the WWVB signal to the west from the original location in Boulder, Colorado. At about $80 \mathrm{~km}$ from the Boulder Laboratories, the site was considered far enough away to prevent the LF and VLF broadcasts from interfering with experiments there. However, it was considered near enough for the driving distance between the station and the laboratory to be reasonable, and for the station frequency to be easily controlled by the Boulder frequency standard [30].

WWVB went on the air in July 1963 from the new facility, initially radiating about $4 \mathrm{~kW}$ at $60 \mathrm{kHz}$, and later raised to $13 \mathrm{~kW}$. The signal was phase-locked using a $50 \mathrm{MHz}$ radio servo link to the cesium frequency standards in Boulder and had a transmitted accuracy of about 2 parts in $10^{11}$ [1]. In August, WWVL began operations at the new site as well, radiating about $500 \mathrm{~W}$ at $20 \mathrm{kHz}$ (later raised to $2 \mathrm{~kW}$ ). A photo of the transmitter building is shown in Fig. 15. Both stations' signals were radiated from four-tower diamond-shaped arrays; an artist's rendition of the antennas is shown in Fig. 16.

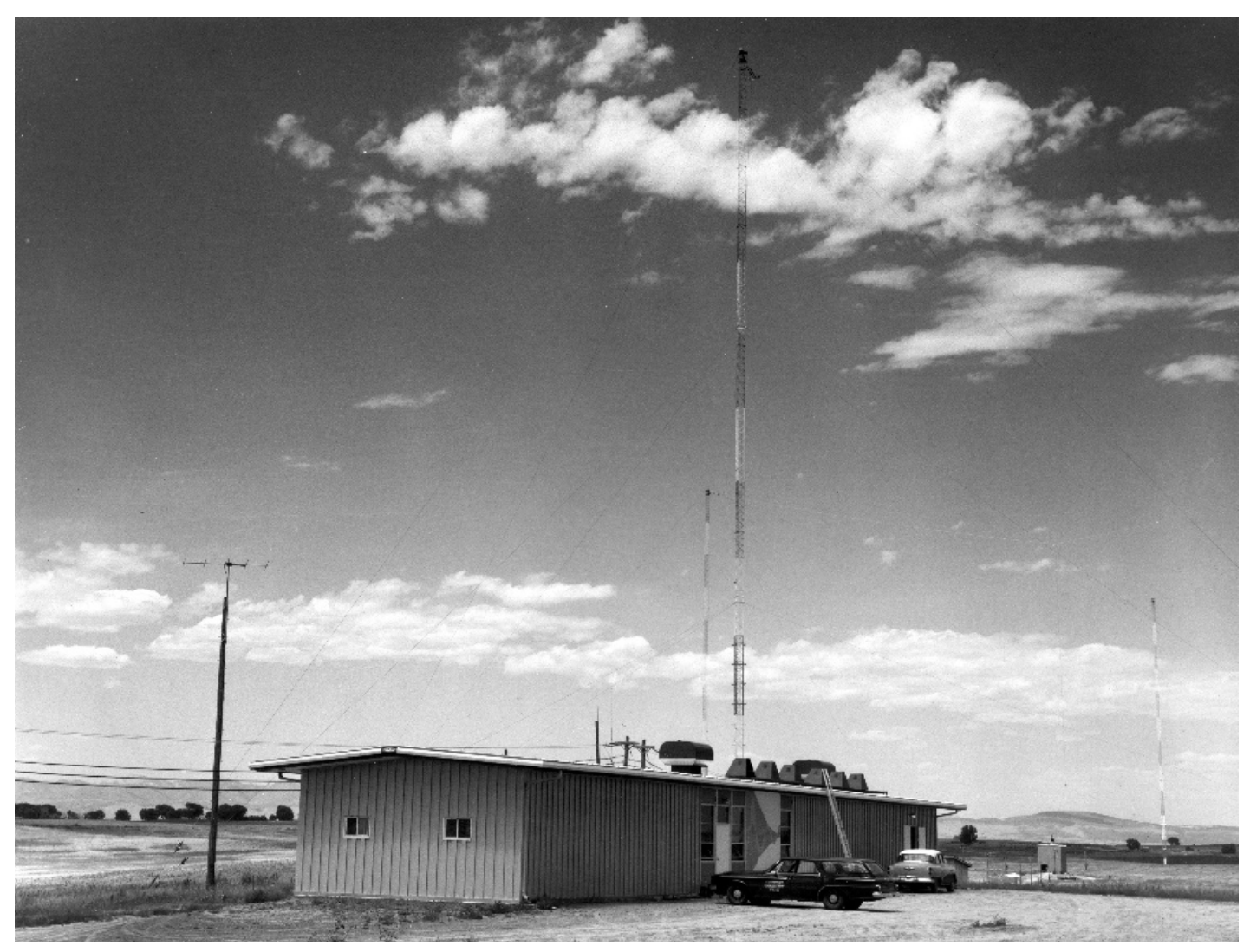

Fig. 15. WWVB building in Colorado, 1963. 


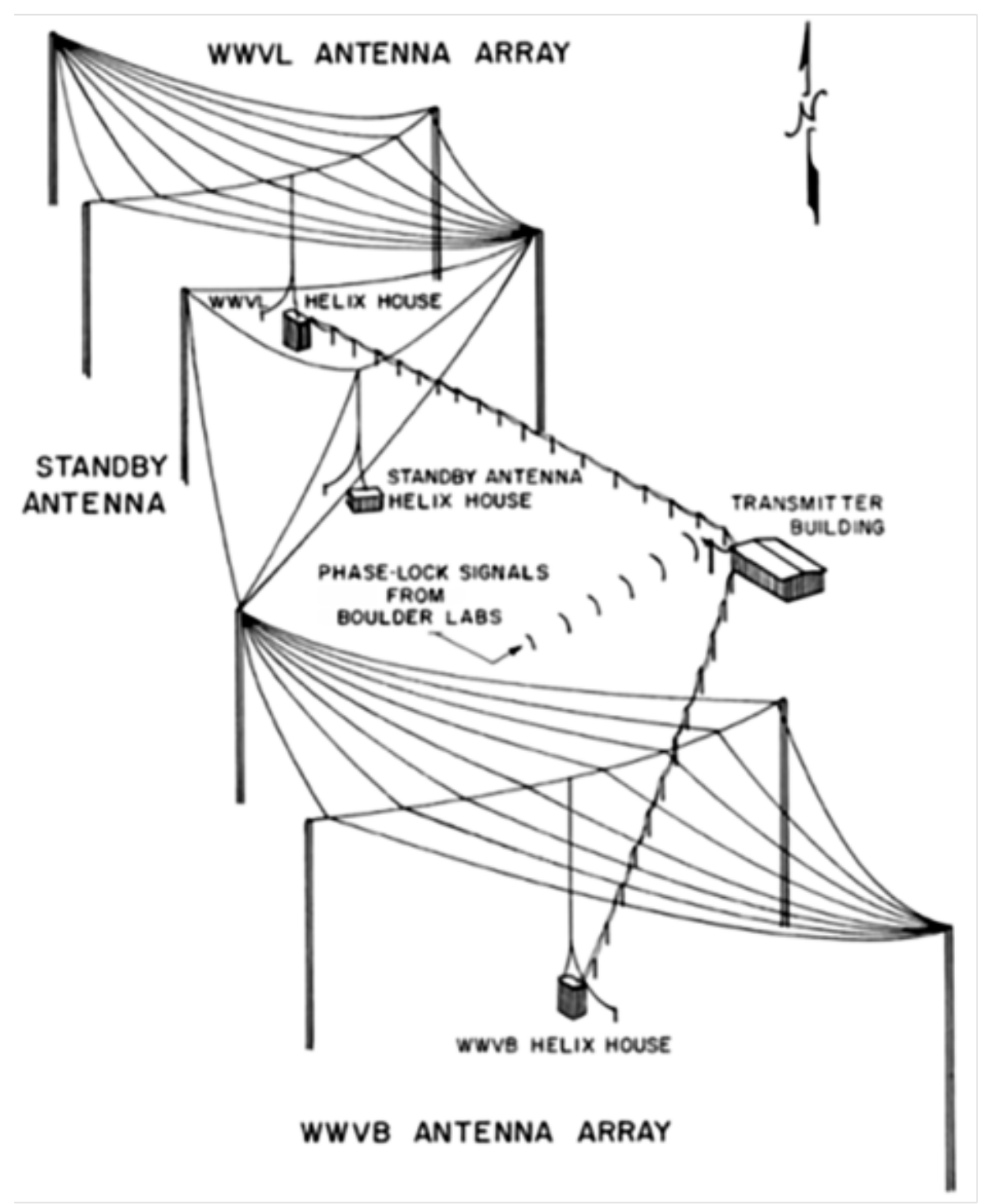

Fig. 16. Artist's conception of the WWVB and WWVL antenna arrays.

Initially, both stations were intended for use as a frequency reference. In 1965, a BCD time code developed by NBS engineer Dave Andrews was implemented on WWVB. This was the first use of a time code on a low-frequency broadcast. Although it initially had few users, it would later become the mostused feature of any of the time and frequency broadcasts [30].

One use of the new WWVB and WWVL signals was to control the WWV and WWVH frequency standards. The comparatively stable propagation paths of the LF and VLF frequencies provided a reliable and easy way to correct the quartz frequency oscillators at the stations in Washington, D.C., and Hawaii. A diagram of this system as it was configured in January 1965 is shown in Fig. 17. 


\section{Journal of Research of the National Institute of Standards and Technology}

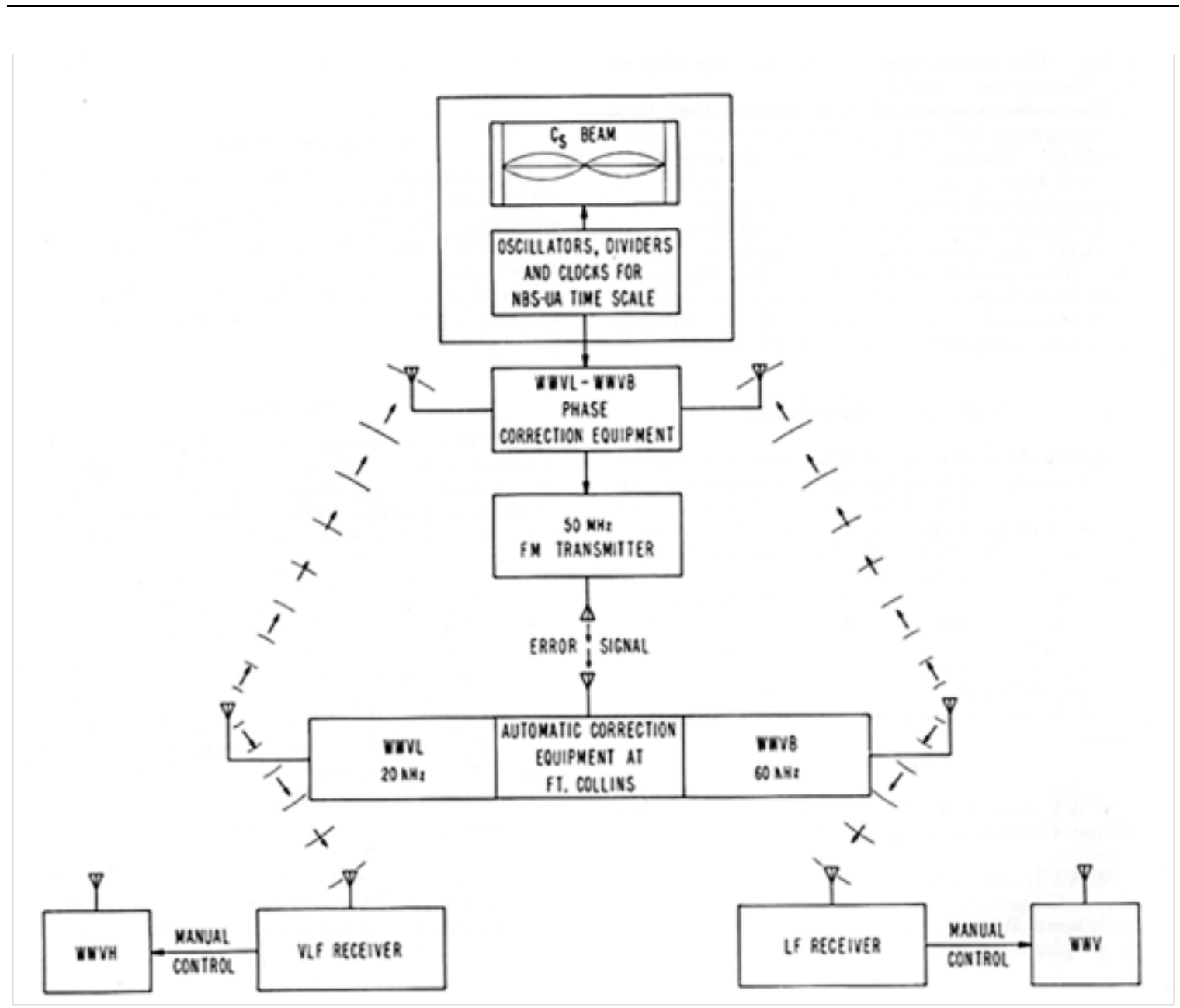

Fig. 17. Frequency control system for WWV, WWVB, WWVL, and WWVH, 1965.

\section{Reorganization}

Several very important events occurred in the mid-1960s that would affect the course of WWV going forward. The first occurred in October 1965, when after some 20 years of being an integral part of NBS, the CRPL was transferred to a new scientific agency called the Environmental Science Services Administration (ESSA), the forerunner of today's National Oceanic and Atmospheric Administration (NOAA). Within ESSA, the name of CRPL was changed to the Institute for Telecommunication Sciences and Aeronomy (ITSA). As a result of the transfer, NBS lost a number of staff members and some radio research facilities to ITSA, which stayed at the same location in Boulder, Colorado. This made NBS less likely to engage in radio research and propagation studies and more likely to focus on using its radio facilities to support measurement and primary standards work. WWV, WWVB, WWVH, and WWVL stayed with NBS and remained a key part of its basic standards work [30].

Next, WWV was on the move again. The idea of moving WWV out of the Washington, D.C., area had been discussed after CRPL's move to Boulder in 1954. With the purchase and development of the large WWVB/WWVL site, those ideas became plans, and in 1966, the plans were executed. Congress had appropriated nearly a million dollars for the development of a new, state-of-the-art facility at the Fort Collins, Colorado, property. Figure 18 shows the new transmitter building under construction; the concrete call letters are the only part of the Greenbelt station that was installed in new Fort Collins facility. 


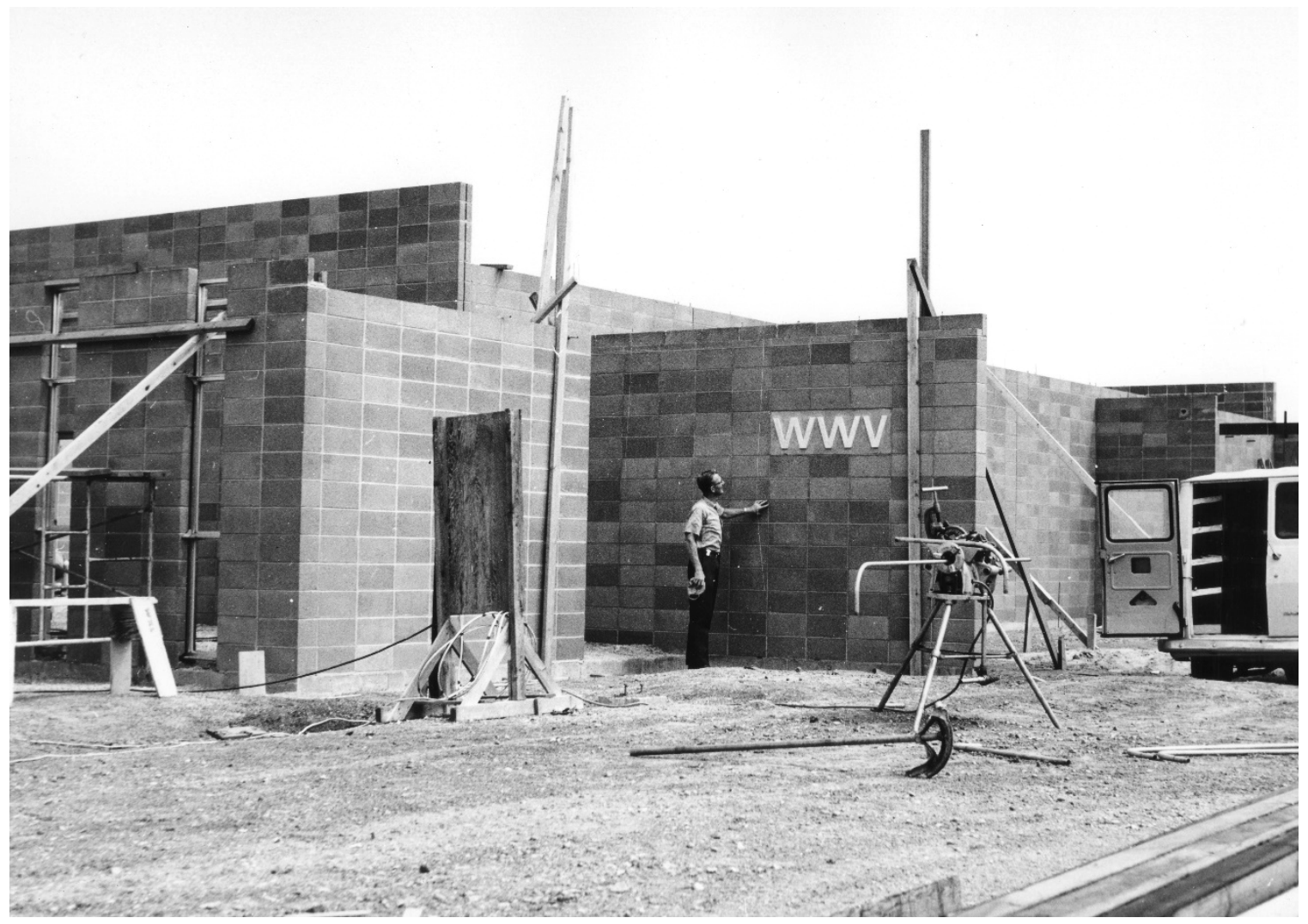

Fig. 18. WWV building under construction in Colorado, 1966. The call letters on the wall were the only parts transferred from the Greenbelt, Maryland, location.

The new station included all new transmitters for each WWV frequency, plus two standby transmitters. The main transmitters were each directly connected to a dedicated half-wave vertical dipole antenna, in the form of guyed steel towers arranged on a low ridge directly to the east of the building. The standby transmitters were connected to broadband antennas capable of carrying any of the six frequencies. A view of the interior showing some of the transmitters is shown in Fig. 19. 


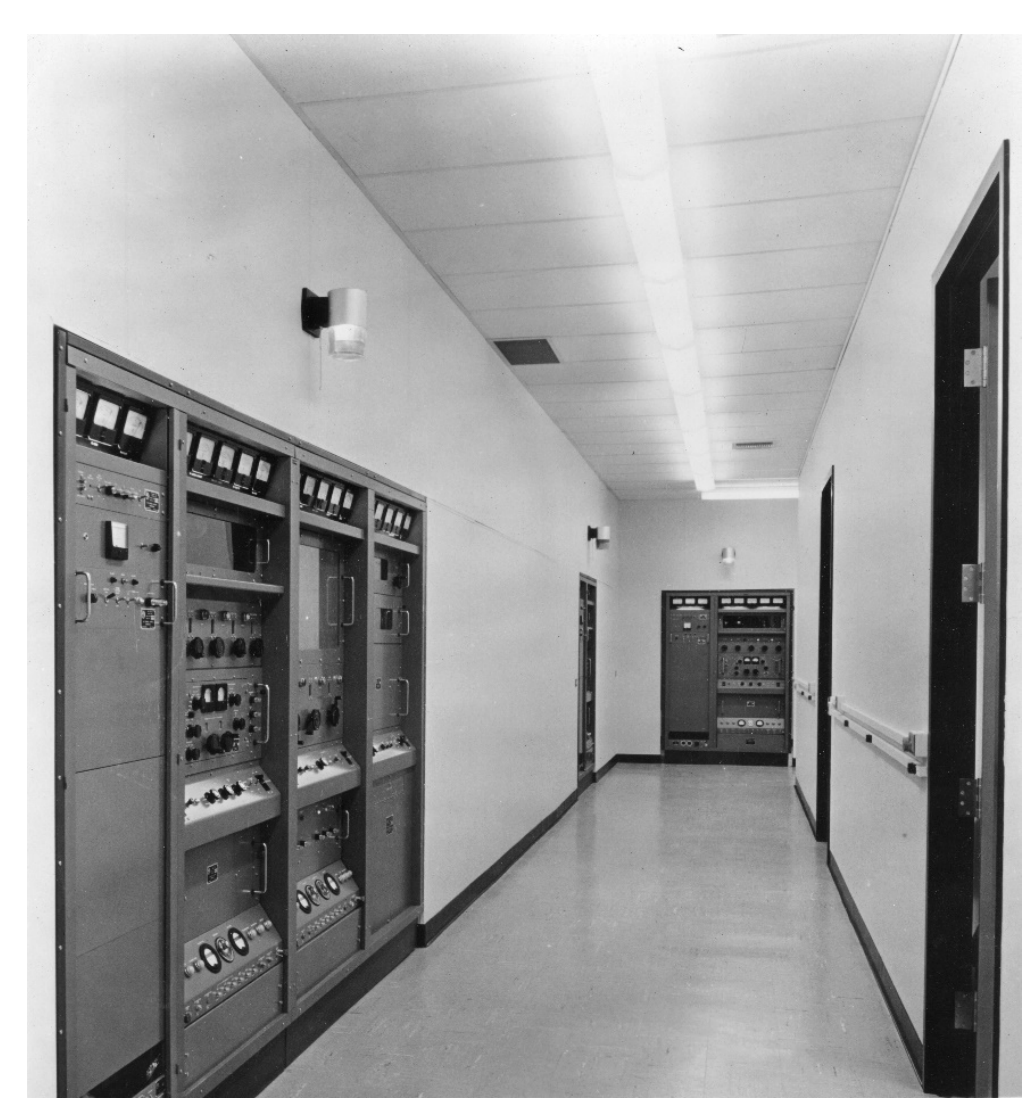

Fig. 19. Interior of WWV building in Fort Collins, Colorado, 1966.

On December 1, 1966, at 0000 h Greenwich Mean Time, the transmitters in Greenbelt, Maryland, were shut down for the last time, and the new station went on the air. WWV was now operating at $10 \mathrm{~kW}$ radiated power on $5 \mathrm{MHz}, 10 \mathrm{MHz}$, and $15 \mathrm{MHz}$, and $2.5 \mathrm{~kW}$ on $2.5 \mathrm{MHz}, 20 \mathrm{MHz}$, and $25 \mathrm{MHz}$. The location near the center of the 48 contiguous states ensured more reliable reception of at least one of the signals from coast to coast [32]. A photo of the WWV building taken in 2001 is shown in Fig. 20. 


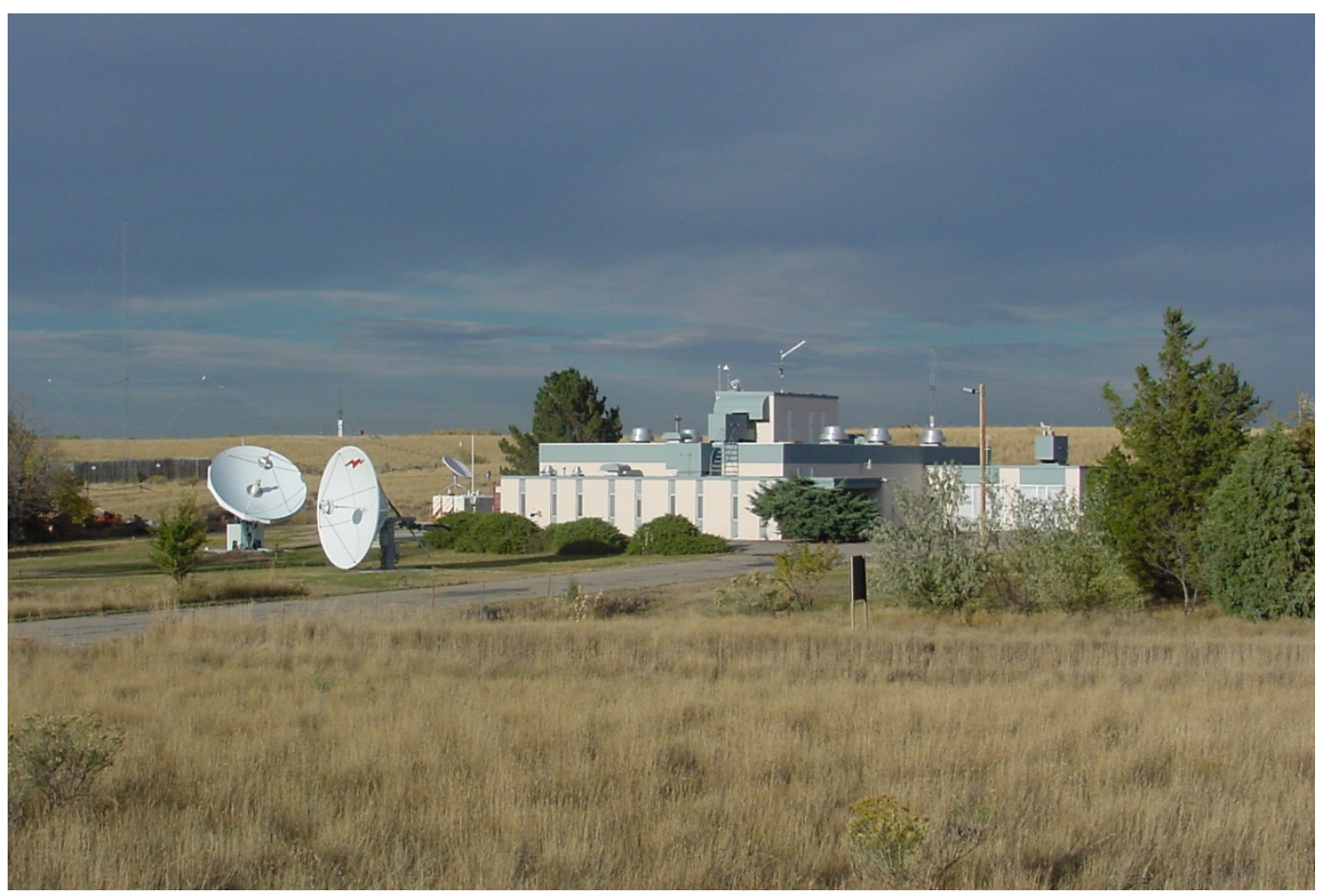

Fig. 20. WWV, 2001.

\section{A New Division}

The third event occurred in 1967 when the Time and Frequency Division of NBS was formed at the Boulder Laboratories. NBS had engaged in many different time and frequency activities for decades, including the development of atomic clocks as well as the operation of the radio stations, but these activities had previously been spread across several groups. Everything was now consolidated into one division [1]. Within the new division, the primary role of the radio stations was to serve as a time and frequency service, a freely available signal source that delivered standard frequency and time signals, referenced to the national standard, to the American public. Accuracy, as always, remained important, but reliability became almost equally important.

The year 1967 was also when, by international agreement, the second was defined as the duration of 9,192,631,770 periods of the electromagnetic radiation associated to the hyperfine transition of the ground state of the Cs133 atom. The redefined second officially began the era of atomic timekeeping. In April of that year, WWV and WWVH began broadcasting the time of day in Greenwich Mean Time (GMT), rather than the local time at the stations.

The new radio station site in Fort Collins received commercial cesium frequency standards that were compared regularly with the atomic frequency standard in Boulder. The comparisons were initially done with the very-high-frequency (VHF) radio servo system in use at WWVB, but in May of 1968, this system was replaced with a common-view comparison of a local television signal that improved the accuracy of the transmitted WWV frequency by a factor of 10 , to 2 parts in $10^{11}$ [30].

\section{WWV QSL Cards}

Throughout the decades, WWV has sent QSL cards to listeners who write the station with details of receiving the WWV signal. These reception reports played an important role in determining how far the WWV signal was propagating, and how well the service was meeting the needs of the public. A card acknowledging reception of WWV in Greenbelt, Maryland, or WWVH on Maui, Hawaii, can be seen in Fig. 21. 


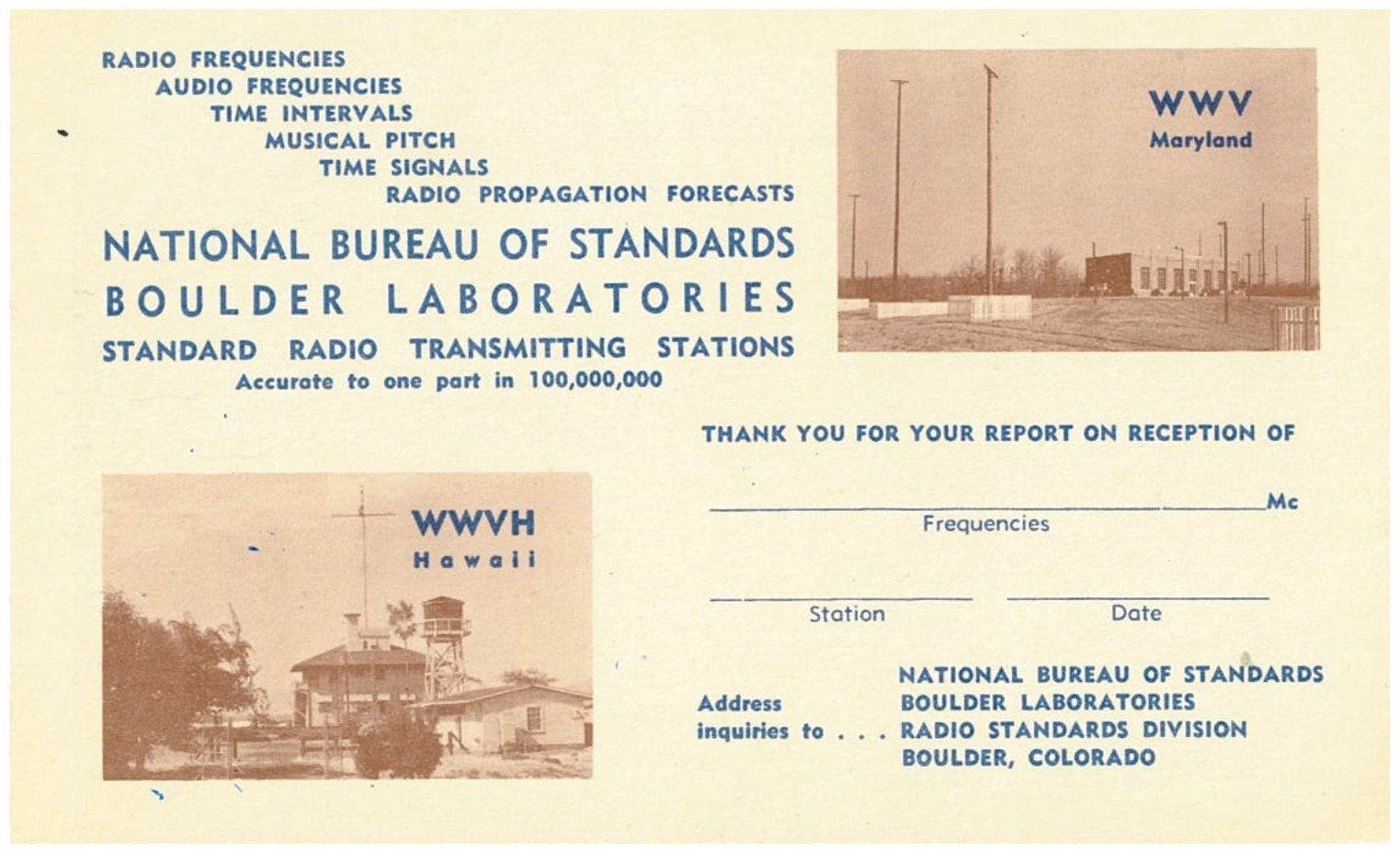

Fig. 21. QSL card acknowledging reception of WWV or WWVH.

A special card was printed for WWV's first day of operation at the new Fort Collins site in 1966 (Fig. 22); NBS received about 10,000 requests for this card [1].

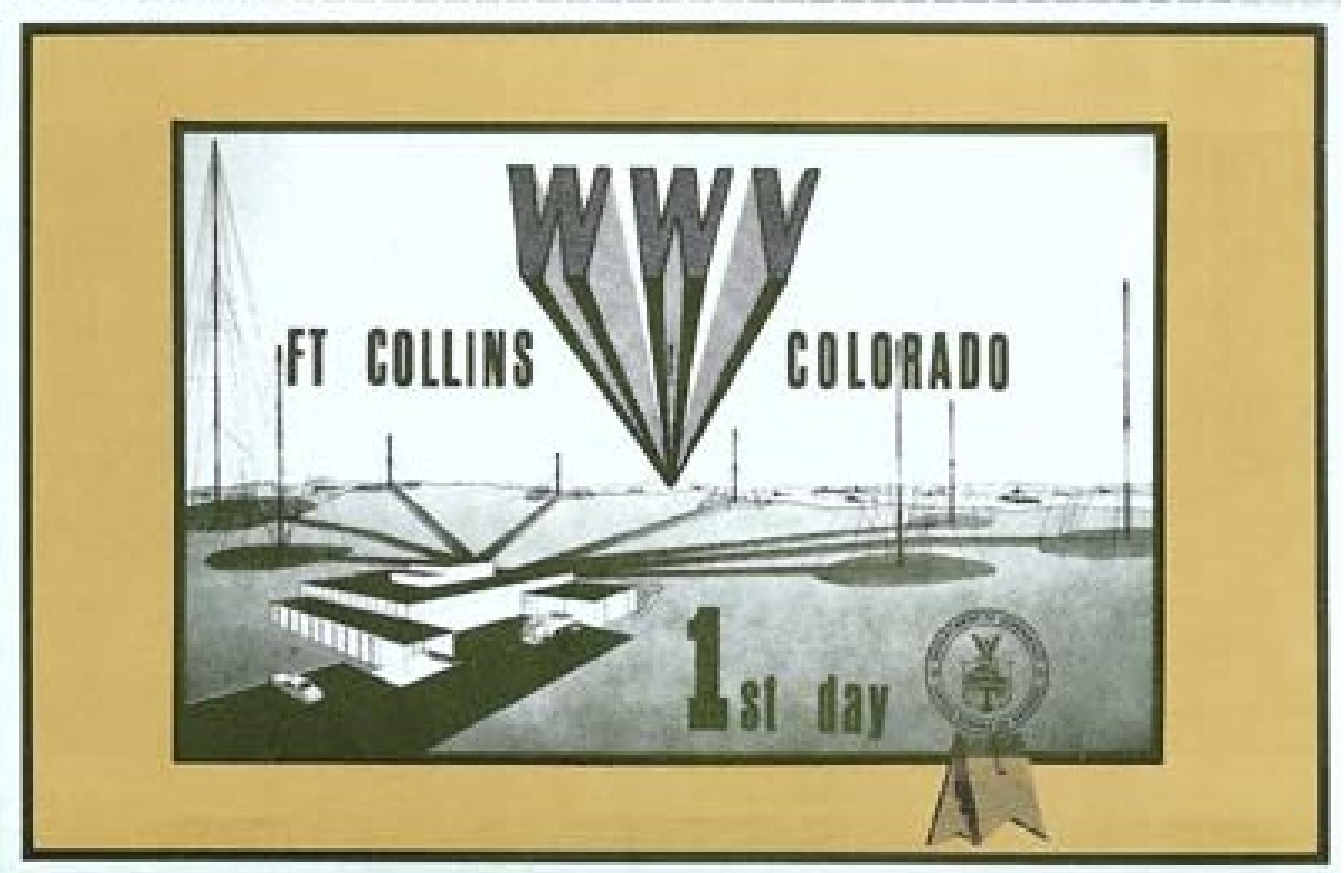

Fig. 22. WWV Fort Collins first-day QSL card, 1966. 
The current WWV QSL card also dates from that era (Fig. 23).

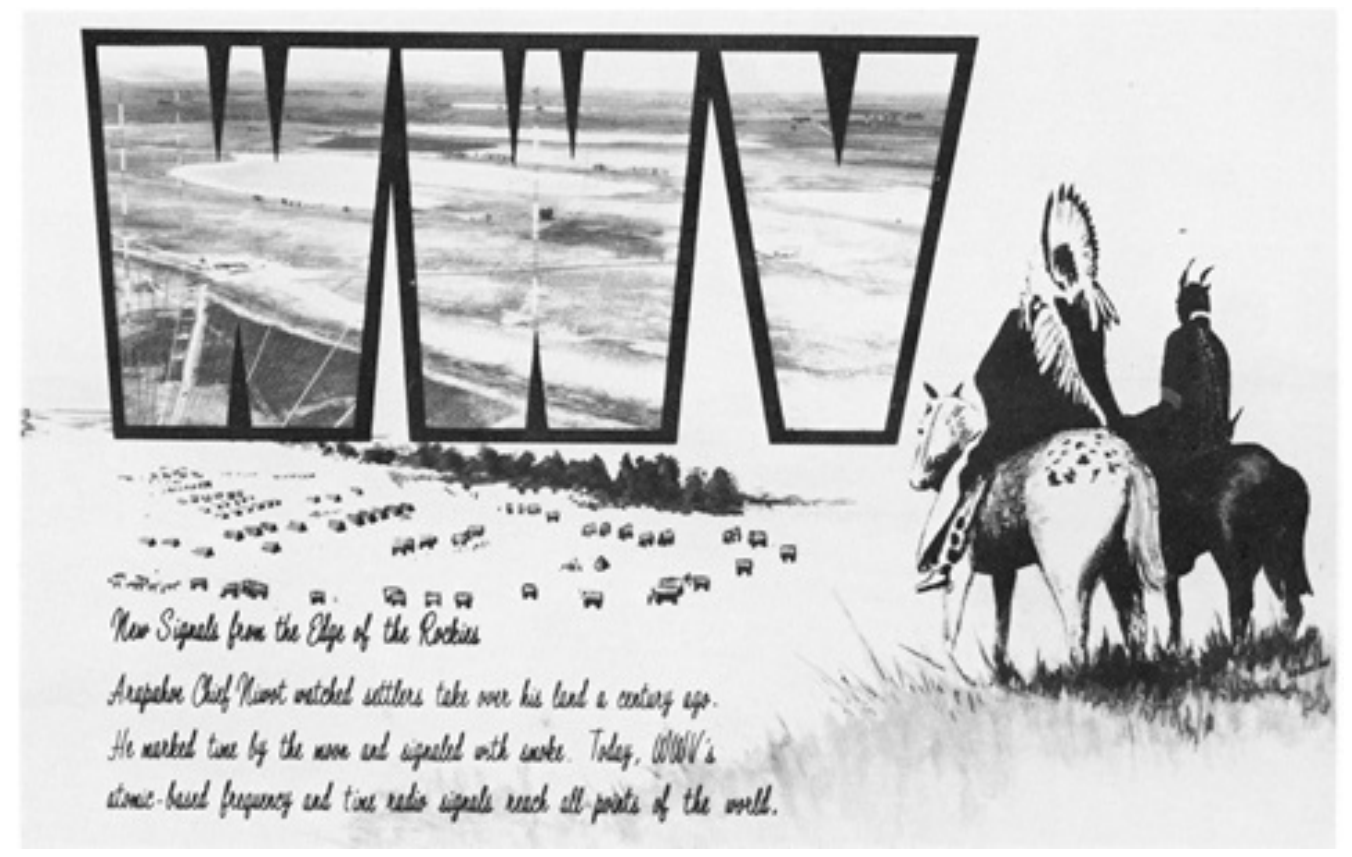

Fig. 23. Current WWV QSL card.

\section{1970s}

The 1970s brought more changes to WWV, and the broadcasts began to take the format they hold today. Many changes were implemented on July 1, 1971. Beginning on that date, the time announcements were made every minute rather than every $5 \mathrm{~min}$, and telegraphic code time announcements were dropped. A $500 \mathrm{~Hz}$ audio frequency was added to the broadcast in addition to the $440 \mathrm{~Hz}$ and $600 \mathrm{~Hz}$ tones, and the geoalerts and propagation forecasts were now in voice rather than telegraphic code [1]. The 36 bit NASA time code was replaced with a modified IRIG-H code, with 1 bit-per-second modulating a $100 \mathrm{~Hz}$ subcarrier. This new code included a daylight saving time (DST) indicator [29].

Another service introduced on July 1971 was the telephone time-of-day service, which made the WWV audio signal available over the telephone system. Users could dial a Boulder telephone number, 303499-7111, and be connected to the live audio feed for about $2 \mathrm{~min}$. By the middle of the decade, the calling rate was about a million calls per year [1], and it is still in operation today. Due to uncertainties imposed by the telephone network, accuracy of the received signal is limited to about $30 \mathrm{~ms}$ over landlines [29].

In 1972, the $20 \mathrm{kHz}$ WWVL broadcast was discontinued, due primarily to the advancement of other VLF services such as the OMEGA and LORAN-C navigation systems and the advent of satellite systems capable of covering large areas of Earth with very little power and with improved accuracy due to very stable signal paths.

The first leap second was inserted in the WWV broadcast on June 30, 1972; in January 1974, the station began broadcasting Coordinated Universal Time (UTC). A survey of WWV users conducted in 1975 indicated that $10 \mathrm{MHz}$ was the most-used frequency, and $20 \mathrm{MHz}$ and $25 \mathrm{MHz}$ were the least used frequencies. In February 1977, the $20 \mathrm{MHz}$ and $25 \mathrm{MHz}$ broadcasts were discontinued, along with the 20 $\mathrm{MHz}$ broadcast at WWVH as an energy-saving measure; due to user demand, the WWV $20 \mathrm{MHz}$ frequency was restored in December 1978 [1]. 


\section{The 1980s and 1990s}

In 1988, NBS became the National Institute of Standards and Technology (NIST), and the WWV broadcasts continued as before, operating as part of the Time and Frequency Division. New, more energyefficient transmitters were procured in 1990 for the $5 \mathrm{MHz}, 10 \mathrm{MHz}$, and $15 \mathrm{MHz}$ broadcasts, and the old transmitters were relegated to standby status. In 1991, the magnetic drum recorders that managed the voice announcements, complicated mechanical systems that were becoming increasingly prone to failure, were replaced with a solid-state electronic voice storage system using digitized audio recordings. This change required a new voice announcement and a new voice.

It is believed that the original voice of WWV was Mr. Don Elliot Heald, of the Audichron Company of Atlanta, Georgia. The manufacturer of the new time code generator (where the voice was stored) auditioned several announcers and finally settled on a voice that closely replicated that of Mr. Heald. It is believed the "new" voice was that of Mr. John Doyle. The WWVH broadcasts from Hawaii, which used a woman's voice for the time of day announcements, continued to use the voice of Mrs. Jane Barbe, also of the Audichron Co., in their new equipment. A typical time of day announcement on either station reads: "At the tone, 17 hours, 43 minutes, Coordinated Universal Time” followed by a $1000 \mathrm{~Hz}$ tone at WWV and a $1200 \mathrm{~Hz}$ tone at WWVH. The station identification announcements include the call sign, a brief description of the content, broadcast frequencies, and the mailing address of the radio stations.

With the new time code generators came year information added to the WWV time code, and an improved DST notification.

Even with the new equipment at WWV, the biggest change to the Fort Collins site in the 1990s was the upgrade to the WWVB $60 \mathrm{kHz}$ service. The World War II-era transmitters were replaced with more powerful, refurbished U.S. Navy units, which were originally used to broadcast to submarines. The antenna system was also refurbished, and the old WWVL antenna was reconfigured to work with the WWVB signal. New control and automatic tuning systems were designed and installed, and, by the end of the decade, the radiated power had increased from $13 \mathrm{~kW}$ to $50 \mathrm{~kW}$ (and later to $70 \mathrm{~kW}$ ). An aerial view of the WWVB site is shown in Fig. 24.

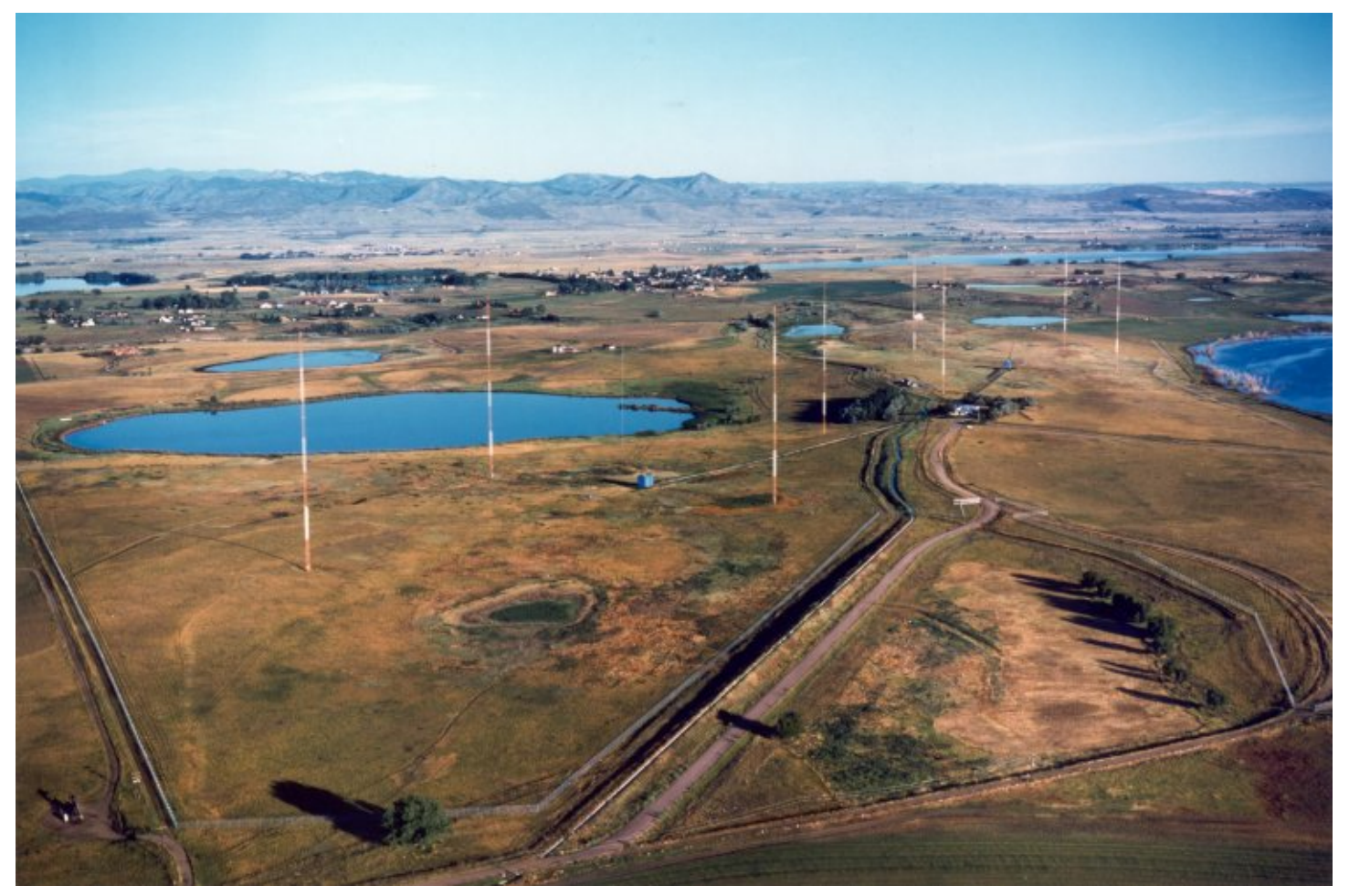

Fig. 24. Aerial view of WWVB, looking northwest. 
As newer methods for disseminating time and frequency information became more readily available, the signals provided by WWV began to take on a lower profile. Time and frequency signals via satellite had been pursued at NBS/NIST since the 1960s; ironically, NBS' first attempt at a satellite time service involved rebroadcasting the WWV audio signal using a NASA satellite. The experiment, called WWVS, began operating in 1971 and transmitted the WWV signal from NASA's ATS-3 satellite during two 15 min periods each weekday, covering about $40 \%$ of the surface of Earth. Using a special slide rule provided by NBS, users could predict the path delay from the geostationary satellite to their location. This provided a combined uncertainty of less than $50 \mu$ s for the WWVS signal, which was much more accurate than the WWV signal as received over any of its HF frequencies. The project ran for about 2 years, but it was supplanted by the GOES Time Code Service, which used two geostationary NOAA weather satellites and, as the name indicates, its own dedicated time code, the first ever broadcast by satellite. The GOES satellites were launched in 1974, and the time service was declared operational in 1977. It remained in service until 2004 [33].

The introduction of the Global Positioning System (GPS) beginning in the 1980s was a game-changer for users of precise time and frequency. Each GPS satellite has cesium clocks on board controlled by USNO and continuously broadcasts the time of day and its position. Scientific and institutional users can, with proper equipment and techniques, obtain timing signals accurate to a few nanoseconds and frequency accuracy of $4 \times 10^{-14}$ worldwide [34]. The impact of GPS was felt across NIST, eventually making GOES obsolete, and changing the user base of the remaining time and frequency broadcast services. Laboratory users now had access to reliable precision timing and frequency signals from multiple satellites with a basic GPS receiver and outdoor antenna, without the need for cumbersome averaging techniques and free from the vagaries of ionospheric disturbances.

\section{The New Millennium: 2000 to the Present}

Technological advances such as GPS altered the landscape, but the need for reliable terrestrial time signals did not go away as the new millennium dawned. Concurrent with the development of the GPS system was the advent of inexpensive WWVB receivers designed for the consumer market. The idea of a wall clock or wristwatch that was always correct and did not need to be adjusted for DST was attractive, and several manufacturers invested in the concept by producing commercially available radio-controlled clocks. The $60 \mathrm{kHz}$ WWVB signal is usable inside most buildings without an external antenna. In 2012, a phase-modulated time code was added to the WWVB broadcast, designed to be more reliable in fringe or difficult reception areas without disabling the legacy pulse-width code used for decades (although the new code did cause the remaining phase-tracking receivers used in laboratory settings to become obsolete) [35]. Today, millions of consumer radio-controlled devices are in use, and WWVB is by far the most-used NIST radio time broadcast.

The HF signals of WWV continue to be broadcast. Beginning in 2006, the original WWV transmitters operating at $2.5 \mathrm{MHz}$ and $20 \mathrm{MHz}$ and the standby units were replaced with more modern transmitters passed along by the U.S. Navy. This newer equipment made it possible to restore the $25 \mathrm{MHz}$ broadcast that had been off the air since 1977.

As of this writing, WWV operates on six frequencies: $2.5 \mathrm{MHz}, 5 \mathrm{MHz}, 10 \mathrm{MHz}, 15 \mathrm{MHz}, 20 \mathrm{MHz}$, and $25 \mathrm{MHz}$. The radiated power is $10 \mathrm{~kW}$ on the $5 \mathrm{MHz}, 10 \mathrm{MHz}$, and $15 \mathrm{MHz}$ frequencies and $2.5 \mathrm{~kW}$ on the rest. All frequencies use a half-wave vertical dipole antenna, and all frequencies except $25 \mathrm{MHz}$ have a dedicated standby transmitter that starts automatically in case of main transmitter failure [36]. Figure 25 shows the site layout as it is today; the antenna labeled "15 MHz STBY" is now the $25 \mathrm{MHz}$ antenna. Figure 26 is an aerial view of the WWV site, with the flashing strobe on top of the $2.5 \mathrm{MHz}$ tower in the foreground. 


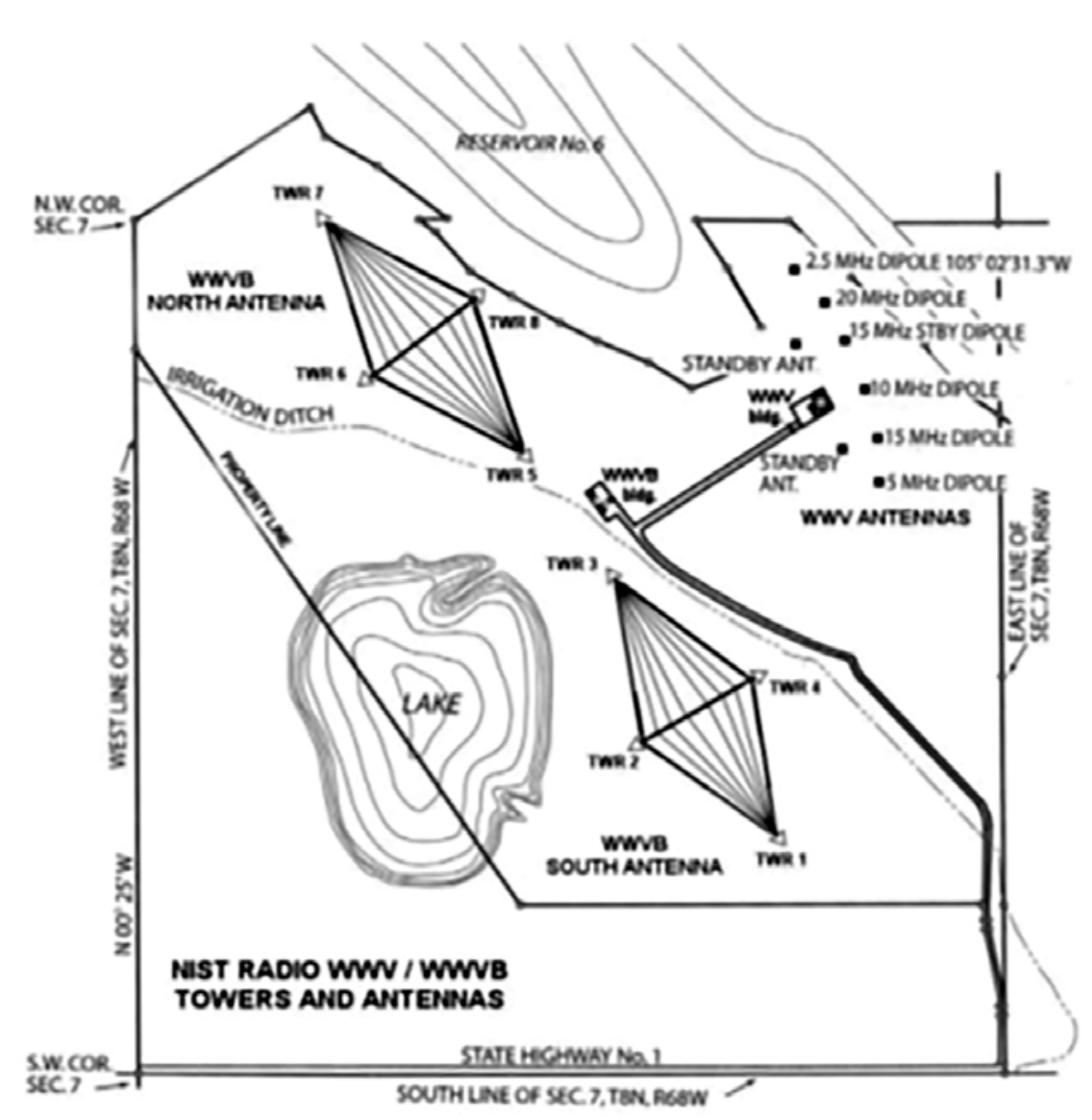

Fig. 25. NIST Radio Station site showing WWV and WWVB.

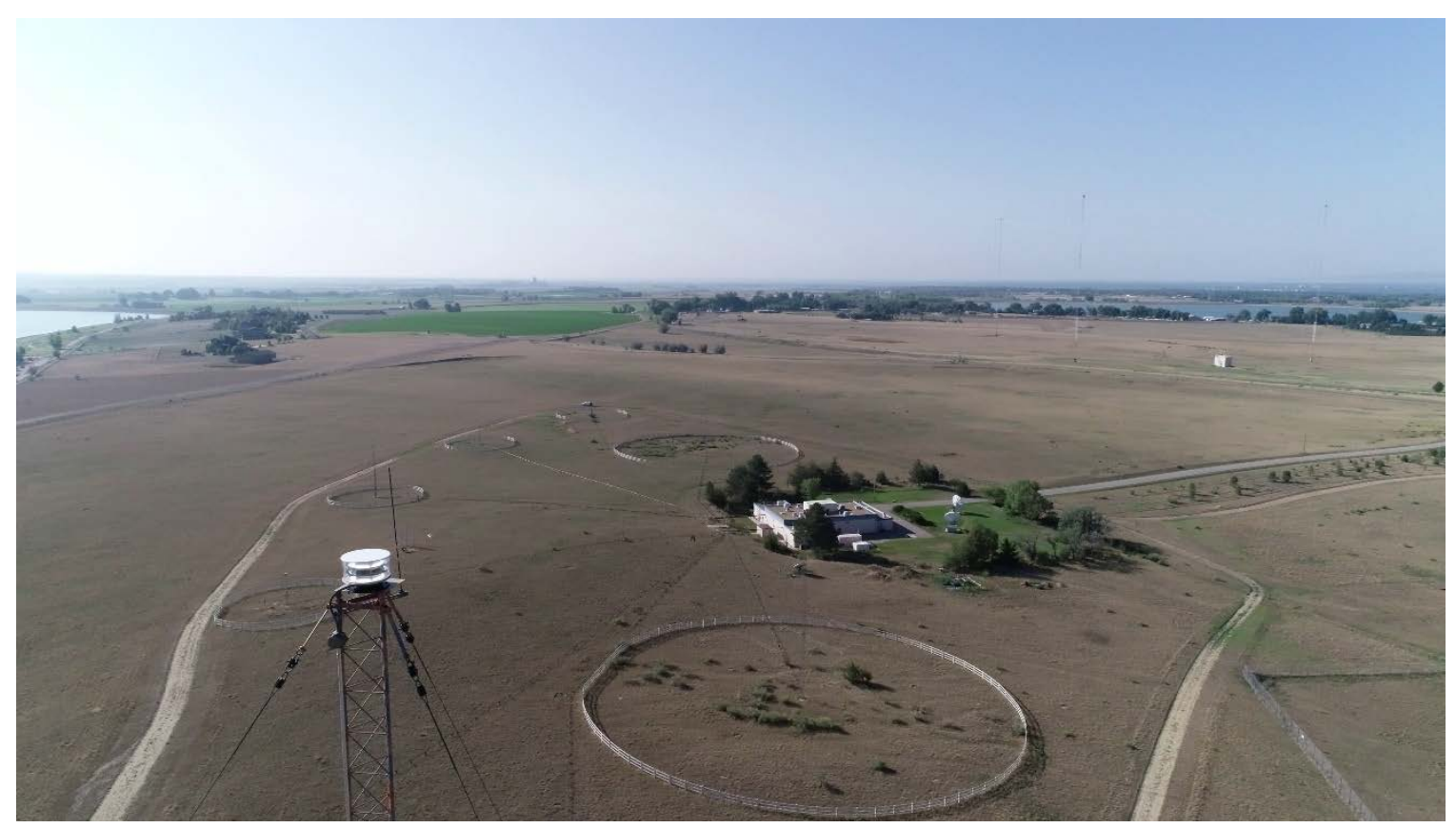

Fig. 26. Aerial view of the WWV site with the $2.5 \mathrm{MHz}$ antenna in the foreground. 


\section{Journal of Research of the National Institute of Standards and Technology}

Although the standard frequency, time interval, time of day, and other information once provided solely by WWV are now available from other sources, the WWV broadcasts continue to be an important piece of the nation's technical infrastructure. Current users include, as from the beginning, amateur radio enthusiasts, but also the scientific community and military users to a surprising degree [37].

Many ordinary people still rely on WWV simply to set the clocks and watches in their homes, as indicated by the surge in calls to the telephone time-of-day service after DST each year. After 100 years, WWV is still on the air, still providing accurate and reliable signals, "at the tone."

\section{References}

[1] Snyder WF, Bragaw CL (1986) Achievement in Radio: Seventy Years of Radio Science, Technology, Standards and Measurement at the National Bureau of Standards. U.S. Government Printing Office, Washington, D.C. National Institute of Standards and Technology Special Publication (SP) 555.

[2] Howeth LS (1963) History of Communications-Electronics in the United States Navy. U.S. Government Printing Office, Washington, D.C. https://archive.org/details/historyofcommuni00howe

[3] QST Magazine (1916) Cover of November 1916 issue. https://commons.wikimedia.org/wiki/File:November_1916_QST.djvu

[4] Electrical World (March 3, 1906) Editorial. http://earlyradiohistory.us/1906reg.htm

[5] Austin LW (1905) Detector for very small alternating currents and electrical waves. National Bureau of Standards Bulletin 1(3):435-438. http://dx.doi.org/10.6028/bulletin.023

[6] White TH (2018) Early radio history. http://earlyradiohistory.us/3myst.htm

[7] Commercial and Government Radio Stations of the United States (1921) U.S. Department of Commerce, Bureau of Navigation, Radio Service, Washington, D.C. Edition June 30, 1921.

[8] National Bureau of Standards (1973) WWV’s golden anniversary. Technical News Bulletin June 1973:140-142.

[9] Washington Times (1919) Awed Visitors listen to "Pretty Baby" played by wireless phonograph. Washington Times February 26, 1919:3.

[10] Monthly Report of the Radio Section (October 1919). Unpublished resource located at the National Archives, Broomfield, CO.

[11] Evening Star Washington DC (1920) Experiments at standards bureau give radio surprise. Evening Star February 21, 1920.

[12] Report of Willis L. Moore, Chief of the Weather Bureau. U.S. Department of Agriculture, Washington, D.C. August $28,1900$. https://earlyradiohistory.us/agric.htm

[13] Dellinger JH (1923) Reducing the guesswork in tuning. Radio Broadcast 3:241.

[14] Monthly Report of the Radio Section (December 1922) Resource located at the National Archives, Broomfield, CO.

[15] QST Magazine (October 1924) The Standard-Frequency Set at WWV. QST Magazine 8(3):9-12.

[16] Semi-Annual Report of the Radio Section (December 1919) Unpublished resource located at the National Archives, Broomfield, CO.

[17] Gilmore CS (2004) Fred Terman at Stanford University: Building a Discipline, a University, and Silicon Valley. Stanford University Press, Palo Alto, CA.

[18] QST Magazine (October 1924) Standard short waves for both coasts at last. QST Magazine 8(3):27.

[19] QST Magazine (May 1927) Standard frequency transmissions. QST Magazine 11(5):50.

[20] Cochrane RC (1966) Measures for Progress: A History of the National Bureau of Standards. U.S. Government Printing Office, Washington, D.C.

[21] Rosa EB (1921) Letter to the Editor. QST Magazine, June 1921.

[22] Mickey L, Martin AD (1934) Development of standard frequency transmitting sets. Journal of Research of the National Bureau of Standards. http://tf.nist.gov/general/pdf/1616.pdf

[23] QST Magazine (July 1936) Schedules for WWV. QST Magazine 20(7):64.

[24] Evening Star Washington DC (1940) Fire destroys radio station at Beltsville. Evening Star November 6, 1940.

[25] National Bureau of Standards (1941) News Release: Status of WWV Broadcast, March 1941. https://www.nist.gov/document/mar151941pressreleasepdf

[26] Installation notes and sketches, from WWV files. Unpublished.

[27] National Bureau of Standards (1961) Standard Frequencies and Time Signals from NBS Stations WWV and WWVH. U.S. Department of Commerce, National Bureau of Standards, Gaithersburg, MD. Miscellaneous Publication 236.

[28] National Bureau of Standards (1943). Official Announcement. U.S. Department of Commerce, National Bureau of Standards, Washington, D.C. https://www.nist.gov/document/wwvbroadcastfromnewfacilitypdf

[29] Nelson G, Lombardi M, Okayama D (2005) NIST Time and Frequency Radio Stations: WWV, WWVH, and WWVB. National Institute of Standards and Technology, Boulder, CO. National Institute of Standards and Technology Special Publication 250-67. https://doi.org/10.6028/NIST.SP.250-67

[30] Lombardi M, Nelson G (2014) WWVB: A half century of delivering accurate frequency and time by radio. Journal of Research of the National Institute of Standards and Technology 119:25-54. https://doi.org/10.6028/jres.119.004

[31] National Bureau of Standards (1960) Experimental Timing Code Added to WWV Broadcasts. U.S. Department of Commerce, Washington, D.C. NBS Summary Technical Report 2492.

https://nistdigitalarchives.contentdm.oclc.org/digital/collection/p16009coll4/id/6255/ 
[32] Beers Y (1967) WWV moves to Colorado. QST Magazine 51(January 1967).

[33] Lombardi M, Hanson W (2005) The GOES Time Code Service, 1974-2004: A retrospective. Journal of Research of the National Institute of Standards and Technology 110(2):79-96. https://doi.org/10.6028/jres.110.008

[34] Parker T, Matsakis D (2004) Time and frequency dissemination: Advances in GPS transfer techniques. GPS World 15(November 2004):32-38. https://tsapps.nist.gov/publication/get_pdf.cfm?pub_id=921052

[35] Radio Station WWVB website. https://www.nist.gov/pml/time-and-frequency-division/radio-stations/wwvb

[36] Radio Station WWV website. https://www.nist.gov/pml/time-and-frequency-division/radio-stations/wwv

[37] Helmboldt JF, Clarke TE, Craig J, Dowell JD, Ellingson SW, Hartman JM, Hicks BC, Kassim NE, Taylor GB, Wolfe CN (2013) Passive all-sky imaging radar in the HF regime with WWV and the first station of the Long Wavelength Array. Radio Science 48(5):491-512. https://doi.org/10.1002/rds.20056

\begin{abstract}
About the author: Glenn K. Nelson has been an electronics technician at Radio Stations WWV and WWVB since 1997. The broadcast stations are part of the Time and Frequency Division of the Physical Measurement Laboratory at NIST. The National Institute of Standards and Technology is an agency of the U.S. Department of Commerce.
\end{abstract}

